\title{
Managers and Productivity Differences
}

\author{
Nezih Guner, Andrii Parkhomenko and Gustavo Ventura*
}

December 2015

\begin{abstract}
We document that for a group of high-income countries (i) mean earnings of managers tend to grow faster than for non managers over the life cycle; (ii) the earnings growth of managers relative to non managers over the life cycle is positively correlated with output per worker. We interpret this evidence through the lens of an equilibrium life-cycle, span-of-control model where managers invest in their skills. We parameterize this model with U.S. observations on managerial earnings, the size-distribution of plants and macroeconomic aggregates. We then quantify the relative importance of exogenous productivity differences, and the size-dependent distortions emphasized in the misallocation literature. Our findings indicate that such distortions are critical to generate the observed differences in the growth of relative managerial earnings across countries. Thus, observations on the relative earnings growth of managers become natural targets to discipline the level of distortions. Distortions that halve the growth of relative managerial earnings (a move from the U.S. to Italy in our data), lead to a reduction in managerial quality of $27 \%$ and to a reduction in output of about $7 \%-$ more than half of the observed gap between the U.S. and Italy. We find that crosscountry variation in distortions accounts for about $42 \%$ of the cross-country variation in output per worker gap with the U.S.
\end{abstract}

Key Words: Managers, Management Practices, Distortions, Size, Skill Investments, Productivity Differences.

JEL Classification: E23, E24, J24, M11, O43, O47.

\footnotetext{
*Guner, ICREA-MOVE, Universitat Autonoma de Barcelona, Barcelona GSE (email: nezih.guner@movebarcelona.eu); Parkhomenko, Universitat Autonoma de Barcelona and Barcelona GSE (email: parkhomenko.andrii@gmail.com); Ventura, Arizona State University (email: Gustavo.Ventura@asu.edu). Guner acknowledges financial support from Spanish Ministry of Economy and Competitiveness, Grant ECO2011-28822 and from from the Generalitat of Catalonia, Grant 2014SGR 803. Parkhomenko acknowledges financial from the FPI Severo Ochoa Scholarship from the Ministry of Science and Innovation of Spain. We thank Francisco Buera and Nicolas Roys for detailed comments. We also thank workshop and conference participants at Annual Meetings of the Spanish Economic Association, Cornell- Penn State Macro Workshop, CREI, EEA-2015, Federal Reserve Bank of Philadelphia, IMF Macroeconomic Policy and Income Inequality Workshop, NBER Summer Institute (Productivity and Macroeconomics), Ohio State, RIDGE-BCU Workshop on Productivity Growth, Resource Misallocation and Development, 2015 Conference on Economic Development (Montreal) and SED-2015 for comments.
} 


\section{Introduction}

Development accounting exercises conclude that productivity differences are central in understanding why some countries are richer than others (Klenow and Rodriguez-Clare, 1997; Prescott, 1998; Hall and Jones, 1999; Caselli, 2005). What does determine cross country productivity differences?

A growing literature emphasizes differences in management practices as a source of productivity differences; see Bloom and Van Reenen (2011) and Bloom, Sadun and Van Reenen (2014), among others. Management practices differ greatly, both across countries and across firms within a given country, and better management practices are associated with better performance (total factor productivity, profitability, survival etc.). U.S. firms on average have the best management practices, and the quality of management declines rather sharply as one moves to poorer countries.

In this paper, we present novel evidence on the earnings of managers and their relation with output per worker. We first document that age-earnings profiles of managers differ non trivially across countries. Using micro data for a set of high-income countries, we show that earnings of managers grow much faster than the earnings of individuals who have nonmanagerial occupations in most countries. In the United States, the earnings of managers grow by about $75 \%$ during prime working ages (between ages 25-29 to 50-54), while the earnings growth for non-managers is about $40 \%$. This gap is weaker in other countries in our sample. In Belgium, for instance, earnings growth of managers in prime working years is about $65 \%$ whereas earnings growth of non-managers is similar to the U.S. On the other extreme, we find that in Spain the earnings of non-managers grow more than those of managers over the life-cycle.

We subsequently document that there is a strong positive relation between the relative steepness of age-earnings profiles and GDP per worker: managerial earnings grow faster than non-managerial earnings in countries with higher GDP per worker. The correlation coefficient between the log of relative earnings and log-GDP per worker is 0.49 , and stable across several robustness checks on our data. Since better management practices and the GDP per worker are positively correlated in the data, there is also a very strong positive relation between the earnings growth of managers relative to the earnings growth of non managers and the quality of management practices across countries. Furthermore, these 
cross-country relations hold only when we look at the relative earnings growth of managers vs. non-managers (workers). There is no systematic relation between GDP per worker and the relative earnings growths of professionals (lawyers, engineers, doctors etc.) vs. workers, self-employed vs. workers, or college-educated versus non-college educated.

It is, of course, an open question how to interpret differences in managerial practices and quality across countries. In this paper, we offer a natural interpretation. Differences in managerial quality emerge from differences in selection into management work, along the lines of Lucas (1978), and differences in skill investments, as we allow for managerial abilities to change over time as managers invest in their skills. Hence, we place incentives of managers to invest in their skills and the resulting endogenous skill distribution of managers and their incomes at the center of income and productivity differences across countries.

We study a span-of-control model with a life-cycle structure along a balanced growth path. Every period, a large number of finitely-lived agents are born. These agents are heterogeneous in terms of their initial endowment of managerial skills. The objective of each agent is to maximize the lifetime utility from consumption. In the first period of their lives, agents make an irreversible decision to be either workers or managers. If an agent chooses to be a worker, her managerial skills are of no use and she earns the market wage in every period until retirement. If an agent chooses to be a manager, she can use her managerial skills to operate a plant by employing labor and capital to produce output and collect the net proceeds (after paying labor and capital) as managerial income. Moreover, managers invest resources in skill formation and, as a result, managerial skills grow over the life cycle. This implies that a manager can grow the size of her production unit and managerial income by investing a part of her current income in skill formation each period.

Skill investment decisions in the model reflect the costs (resources that have to be invested rather than being consumed) and the benefits (the future rewards associated with being endowed with better managerial skills). Since consumption goods are an input for skill investments, a lower level of aggregate productivity results in lower incentives for managers to invest in their skills. We assume that economy-wide productivity grows at a constant rate. In this scenario, we show that the model economy exhibits a balanced growth path as long as the managerial ability of successive generations grows at a constant rate.

A central component of our model is the complementarity between available skills and investments in the production of new managerial skills. More skilled managers at a given 
age invest more in their skills, which propagates and amplifies initial differences in skills over the life cycle. This allows the model to endogenously generate a concentrated distribution of managerial skills. As in equilibrium more skilled managers operate larger production units, the model has the potential to account for the highly concentrated distribution of plant size in data.

We calibrate the model to match a host of facts from the U.S. economy: macroeconomic statistics, cross sectional features of establishment data as well as the age-earnings profiles of managers. We assume for these purposes that the U.S. economy is relatively free of distortions. We find that the model can indeed capture central features of the U.S. plant size distribution, including the upper and lower tails. It also does an excellent job in generating the age-earnings profiles of managers relative to non managers that we document from data.

We then proceed to introduce size-dependent distortions as in the literature on misallocation in economic development. We model size-dependent distortions as progressive taxes on the output of a plant and do so via a simple parametric function, which was proposed originally by Benabou (2002). Size-dependent distortions have two effects in our setup. First, a standard reallocation effect, as the enactment of distortions implies that capital and labor services flow from distorted (large) to undistorted (small) production units. Second, a skill accumulation effect, as distortions affect the incentives for skill accumulation and thus, the overall distribution of managerial skills - which manifests itself in the distribution of plant level productivity. Overall, the model provides us with a natural framework to study how differences among countries in aggregate exogenous productivity and distortions can account not only for differences in output per worker but also for differences in managerial quality, size distribution of establishments and age-earnings profiles of managers.

In consistency with the facts documented above, our model implies that lower levels of economy-wide productivity result both in lower managerial ability as well as in flatter relative age-earnings profiles. A 20\% decline in aggregate productivity lowers investment in skills by managers by nearly $48 \%$, leading to a decline in the average quality of managers of about $10 \%$. With less investment, managerial incomes grow at a slower rate over the life-cycle, generating the positive relation between output per worker and steepness of ageincome profiles that we observe in the data. Lower investment by managers magnifies the effects of lower aggregate productivity, and output per worker declines by about $30 \%$.

We then consider a menu of distortions and evaluate their effects on output, plant size, 
notions of productivity, and age-earnings profiles of managers. When we introduce the sizedependent distortions into the benchmark economy, we find substantial effects on output, the size distribution of plants and the relative steepness of managerial earnings. We show that such steepness is critically affected by distortions, and that distortions can eliminate all differences in the earnings growth of managers to non-managers. We find that distortions that halve the growth of relative managerial earnings (which would correspond to a move from the U.S. to Italy in our data), lead to a reduction in output per worker of about $7 \%$ - corresponding to more than half of the observed output gap between the U.S. and Italy. As a result of both misallocation and skill investment effects, managerial quality declines significantly by nearly $27 \%$.

We find that these results are robust to the consideration of transitions between managerial and non-managerial work over the life cycle. We do this in detail in Appendix III, where we present an extension of the benchmark model with transitions between occupations.

We finally use the benchmark model to assess the combined effects of distortions and exogenous variation in economy-wide productivity. For these purposes, we force the model economy to reproduce jointly the level of output per worker in each country and the relative earnings growth of managers. We do so by choosing economy-wide productivity levels and the level of size dependency of distortions in each country to hit these two observations. We find that distortions are critical in generating relative earnings growth across countries. As a result, observations on relative earnings growth provide us with natural targets to discipline the level of distortions. Once we are able to reproduce both the level of GDP per worker and the relative earnings growth of managers within our model, we can assess the contribution of economy-wide productivity and distortions to cross-country differences in output per worker. To this end, we first allow economy-wide productivity to differ across countries and shut down the distortion channel, and then do the reverse (i.e. we allow distortions to vary and shut down differences in economy-wide productivity). We find that distortions alone account for about $42 \%$ of variation in GDP per worker gap with the U.S. across countries, while the rest of the variation is accounted for by differences in exogenous economy-wide productivity and interaction effects. The level of distortions that reproduce the relative earnings growth of managers in Italy (about half of the relative earnings growth in the US) are able to generate about $43 \%$ of the observed output gap with the US. 


\subsection{Background}

The current paper builds on recent literature that studies how misallocation of resources at the micro level can lead to aggregate income and productivity differences; see Hopenhayn (2014), Restuccia and Rogerson (2013) and Restuccia (2013) for recent reviews. Following Guner, Ventura and Yi (2008) and Restuccia and Rogerson (2008), we focus in this paper on implicit, size-dependent distortions as a source of misallocation. ${ }^{1}$ Unlike these papers, we model explicitly how distortions and economy-wide productivity differences affect managers' incentives to invest in their skills and generate an endogenous distribution of skills. As a result, we show how data on relative earnings growth of managers can be used to infer the degree of distortions within our model.

Our emphasis on age-earnings profiles of managers naturally links our paper to the empirical literature on differences in management practices -see Bloom and Van Reenen (2010), and Bloom, Lemos, Sadun, Scur and Van Reenen (2014) for recent surveys - as well as to the recent development and trade literature that considers amplification effects of productivity differences or distortions due to investments in skills and R\&D. Examples of these papers are Erosa, Koreshkova and Restuccia (2010), Rubini (2011), Atkeson and Burstein (2010, 2011), Gabler and Poschke (2013), Manuelli and Seshadri (2014), and Cubas, Ravikumar and Ventura (2015), among others.

The importance of management and managerial quality for cross-country income differences have been emphasized by others before. Caselli and Gennaioli (2013) was possibly the first paper that highlighted the importance of managers for cross-country income differences. Caliendo and Rossi-Hansberg (2012) analyze how the internal organization of exporting firms changes in response to trade liberalization and the ensuing effects on average productivity. Gennaioli, La Porta, Lopez-de-Silanes and Shleifer (2013) build a span-of-control model of occupational choice with human capital externalities to study income differences across regions. Recent work by Bhattacharya, Guner, and Ventura (2013), Roys and Seshadri (2013), Akcigit, Alp and Peters (2014), and Alder (2014), among others, also study how managers and their incentives matter for aggregate productivity and the size distribution of plants and

\footnotetext{
${ }^{1}$ Other papers have dealt with explicit policies in practice. Garcia-Santana and Pijoan-Mas (2014) and Garicano, Lelarge and Van Reenen (2013) study examples of size-dependent policies in India and France, respectively. Buera, Kaboski and Shi (2011), Cole, Greenwood and Sanchez (2012), and Midrigan and Xu (2014) focus on the role of financial frictions in leading to misallocation of resources.
} 
firms. Differently from these papers, we document novel facts on managerial earnings and use these facts to discipline our model economy. Our emphasis on cross-country differences in managerial earnings also relates our paper to Lagakos, Moll, Porzio and Qian (2013), who study differences in age-earnings profiles, i.e. return to experience, across countries and show that they are flatter in poorer countries. We focus, however, on relative earnings growth of a particular group (managers).

Our paper is also connected to work that documents cross-country differences in plant and firm-level productivity and size. Hsieh and Klenow (2009), Bartelsman, Haltiwanger, and Scarpetta (2013), Hsieh and Klenow (2013) and Garcia-Santana and Ramos (2015) are examples of this line of work. Poschke (2014) builds a model of occupational choice with skill-biased change in managerial technology - managers with better skills benefit more from technological change - to account for cross-country differences in firm size distribution. Bento and Restuccia (2015) document cross-country differences in plant size in manufacturing, and develop a model where distortions affect investments in plant-level productivity. They use this model to draw a mapping from plant size to aggregate productivity differences.

Finally, our paper is related to recent papers that emphasize the link between managerial incentives, allocation of talent and income inequality. Celik (2015) studies how income inequality can affect the allocation of talent between routine production and innovation in an overlapping generations models in which agents can spend resources productively to enhance their skills, or unproductively to create signals about their skills. More closely related to our paper, Jones and Kim (2014) study a model in which heterogeneous entrepreneurs exert effort to generate growth in their incomes and how such effort can create a Pareto-tail for top incomes.

Our paper is organized as follows. Section 2 documents facts on age-earnings profiles for a set of high income countries. Section 3 presents the model and the modeling of distortions. Section 4 discusses the calibration of the benchmark model. Section 5 presents the findings associated to the introduction of differences in exogenous economy-wide productivity and size-dependent distortions. In section 6, we evaluate the importance of skill investments and transitions between managerial and non-managerial work over the life cycle for our findings. Section 7 quantifies the relative importance of distorsions vis-a-vis exogenous productivity differences in accounting for relative managerial earnings growth and output differences across countries. Finally, section 8 concludes. 


\section{Managerial Earnings over the Life Cycle}

In this section, we present age-earnings profiles for managers and non-managers for a group of high-income countries. Panel data on income dynamics are available for a small set of countries and even then since individuals with managerial occupations constitute a small group, it is not possible to construct age-earnings profiles for managers using panel data sets. As a result, we conduct our analysis with large cross-sectional data sets pertaining to different countries.

We use four data sources: The Integrated Public Use Microdata Series-USA (IPUMSUSA), IPUMS-International, Luxembourg Income Study (LIS), and the European Union Statistics on Income and Living Conditions (EU-SILC). IPUMS-International provides harmonized Census data for a large set of countries. Only few international censuses, however, contain information both on incomes and occupations. LIS is another harmonized international data set that contains cross-sectional individual level data on income and other socioeconomic characteristics. Finally, the EU-SILC contains both cross-sectional and longitudinal microdata data for European Union countries on income, work, poverty, social exclusion and living conditions.

Our final sample consists of 20 countries: Australia, Austria, Belgium, Canada, Denmark, Finland, France, Germany, Iceland, Ireland, Israel, Italy, Luxembourg, Netherlands, Norway, Spain, Sweden, Switzerland, the United Kingdom, and the United States. Table A1 in Appendix I shows survey years, data sources, and the number of observations for each country.

We construct age-earnings profiles by estimating earnings equations as a function of age, controlling for year effects and educational attainment. Specifically, for each country we estimate the following regression:

$$
\ln y_{i t}=\alpha+\beta_{1} a_{i t}+\beta_{2} a_{i t}^{2}+\gamma_{t}+\phi e_{i}+\varepsilon_{i t}
$$

where $y_{i t}$ is earnings and $a_{i t}$ is age of individual $i$ in year $t$. The coefficients $\beta_{1}$ and $\beta_{2}$ capture the non-linear relationship between age and earnings, while $\gamma_{t}$ represents year fixed-effects. Finally, $e_{i}$ is an individual dummy variable capturing college education: it is equal to 1 if the individual has a bachelor's degree or higher, and zero otherwise. ${ }^{2}$ In this way we account,

\footnotetext{
${ }^{2}$ The data does not allow us to use a more detailed education variable for all the countries in our sample.
} 
for the fact that countries differ in the educational attainment of their population and could differ in the returns to education. We estimate this equation for individuals with managerial and non-managerial occupations separately.

To estimate equation (1), we restrict the samples to ages 25 to 64 , and group all ages into eight 5-year age groups: 25-29, 30-34, ..., 60-64. Individuals are classified as managers and non-managers based on their reported occupations. Table A2 in Appendix I documents how managers are defined in different data sets. Whenever it is possible, we stick to the occupational classification by International Labor Organization. ${ }^{3}$ The sample is further restricted to individuals who report positive earnings and work full time (at least 30 hours per week). Earnings are defined as the sum of wage \& salary income and self-employment income. Most individuals in our samples earn either wages or self-employment income. However, the samples contain a small number of managers and non-managers who report positive amounts for both types of income.

Figure 1 reports age-earnings profiles for managers and non-managers for the US. Managerial incomes grow by a factor of about 1.75 in prime working years - between ages 25-29 and 50-54 - whereas incomes of non-managers only rise by a factor of 1.4 .

Let the relative income growth, $\hat{g}$ be defined as

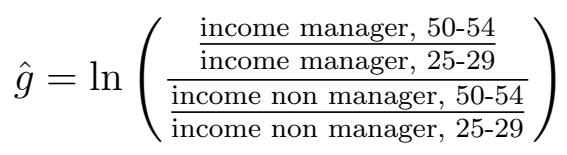

Our key finding is the positive relationship between GDP per worker and the life cycle growth of earnings of managers relative to the growth of non-managerial earnings. ${ }^{4}$ We report this relationship in Figure 2. While the results should be viewed with some caution due to small sample size, the relationship between log-GDP per worker and the steepness of managerial age-earning profiles is remarkably strong. The slope of the fitted line is about 0.57 , and the correlation is 0.49. Consider countries along the fitted line in Figure 2. GDP per worker in Italy is about $12 \%$ lower than the GDP per worker in the U.S. This is associated with an almost $50 \%$ decline in the relative earnings growth for managers ( $\widehat{g}$ declines from 0.22 to

\footnotetext{
${ }^{3}$ An individual is classified as a manager if his/her International Standard Classification of Occupations (ISCO-88) code is 11 ("Legislators, senior officials and managers"), 12 ("Corporate Managers"), or 13 ("General Managers"). We do not use the more recent ISCO-08, since most of our observations are dated earlier than 2008. Source: http://www.ilo.org/public/english/bureau/stat/isco/isco88/major.htm

${ }^{4}$ We use the data on GDP per worker in year 2000 from Penn World Tables 7.1, Heston et al (2012)
} 
0.11). When we go down to Sweden, GDP per worker declines by $25 \%$ from the U.S. level, while the relative earnings growth declines by about 70\% ( $\widehat{g}$ declines from 0.22 to 0.07 ).

Since higher GDP per worker is also associated with better management practices, there is also a very strong relation between the steepness of managerial age-earning profiles and management practices. This relation is shown in Figure 3. In countries with better management practices, such as the US or Germany, managers enjoy much higher relative earnings growth compared to managers in countries with poor management practices, such as Italy. ${ }^{5}$

Robustness We next perform several robustness checks regarding the composition of the sample and the regression equation. First, we exclude the self-employed from the whole sample, i.e. both from managers and non-managers, as well as only from the non-managers category. In the data, self-employed individuals are either those who state that their main source of income is self-employment, or the ones who have positive self-employment income and no wage and salary income. Many self-employed, especially those who report a nonmanagerial occupation, have both managerial and non-managerial duties and hence do not easily fit into our categorization. Figures 4 and 5 show that our results are robust to exclusion of all self-employed and self-employed non-managers.

Second, we narrow the definition of earnings to be wage and salary income only. Under this restriction, the self-employed who earn positive wage and salary income - either as managers or non-managers - are in the sample. However, their income from self-employment is not counted as part of their earnings. Figure 6 illustrates that dropping self-employment income from the notion of earnings does not change our results markedly.

Third, we run our benchmark regression under labor-force weights to control for potential effects associated to country size. As Figure 7 shows, adjusting by country size does not affect our results in any significant way. Finally, we control for work in the finance sector as managerial growth in this sector could arguably be much higher than in the rest of the economy. The results of this exercise are shown in Figures 8. As the figures show, none of these variations affect the central finding that relative earnings growth is positively associated to GDP per worker. We also run an exercise where we control for work in broad sectors (agriculture, manufacturing, services). Our key finding still holds.

\footnotetext{
${ }^{5}$ The data on management practices is taken from Bloom, Genakos, Sadun, and Van Reenen (2012), Table 2.
} 


\subsection{Are Managers Different?}

The main result in this section (Figure 2) indicates that earnings of managers grow faster relative to non-managers in richer countries. In the next section, we build a model economy in which steeper age earnings profiles of managers emerge as the result of higher investments that managers make to enhance their skills over the life-cycle in countries with either higher aggregate productivity or lower distortions. There are of course other non-managerial occupations/professions for which human capital investments over the life cycle arguably plays a key role. Do we observe a similar relation between the relative steepness of age earnings profiles and the GDP per worker for those other professions?

Figure 9 shows the findings when we replicate our exercise in Figure 2 for professionals lawyers, engineers, doctors, etc. - since individuals in this group are likely to be more similar to managers in terms of their incentives to invest in skills. ${ }^{6}$ We look at the earnings growth for professionals (instead of managers) relative to the earnings growth of workers - those who have non-professional, non-managerial occupations - versus GDP per worker. We find that there is no positive relation between GDP per worker and the relative earnings growth of professionals over their life-cycle. In Figure 10, we illustrate our findings when we repeat the same exercise for self-employed individuals - who are often used in applied work to capture the size of entrepreneurial activity in a country. Again, there is no systematic relation between the earnings growth for self employed individuals relative to workers (those who are not self-employed and have non-managerial occupations). Finally, we separate individuals in two broad categories; those with college education - four years or more of university education- and those without. Our results are illustrated in Figure 11. We find in this case a small, near zero, relationship between relative earnings growth and output per worker.

Overall, these results strongly suggest that forces that affect age earnings profiles of managers relative to workers/non-managers are rather specific to the incentives they face, and are unlikely to be due to factors that affect all individuals in the economy, such as non-linear income taxation. We present below a parsimonious model able to capture these key properties of the data.

\footnotetext{
${ }^{6}$ We define professionals as individuals who hold occupations in Group 2 in ISCO-88. Source: http://www.ilo.org/public/english/bureau/stat/isco/isco88/major.htm
} 


\section{Model}

We develop a life-cycle, span-of-control model, where managers invest in their skills. Time is discrete. Each period, a cohort of heterogeneous individuals that live for J periods are born. Each individual maximizes the lifetime utility from consumption, so the life-time discounted utility of an agent born at date $t$ is given by

$$
\sum_{j=1}^{J} \beta^{j-1} \log \left(c_{j}(t+j-1)\right),
$$

where $\beta \in(0,1)$ and $c_{j}(t)$ is the consumption of an age- $j$ agent at date $t$.

Each agent is born with an initial endowment of managerial ability. We denote managerial ability by $z$. We assume that initial (age-1) abilities of an agent born at date $t$ are given by $z_{1}(t)=G_{z}(t) z$, and $z$ is drawn from an exogenous distribution with cdf $F(z)$ and density $f(z)$ on $\left[0, z^{\max }\right]$. That is, individuals are heterogenous in initial managerial ability, and abilities for newborns are shifted in each date by the factor $G_{z}(t)$. We assume that $G_{z}(t)$ grows at the constant (gross) rate $1+g_{z}$.

Each agent is also endowed with one unit of time which she supplies inelastically as a manager or as a worker. In the very first period of their lives, agents must choose to be either workers or managers. This decision is irreversible. If an individual chooses to be a worker, her managerial efficiency units are foregone, and she supplies one efficiency unit of labor at each age $j$. Retirement occurs exogenously at age $J_{R}$. The decision problem of a worker is to choose how much to consume and save every period.

If an individual chooses instead to be a manager, she has access to a technology to produce output, which requires managerial ability in conjunction with capital and labor services. Hence, given factor prices, she decides how much labor and capital to employ every period. In addition, in every period, a manager decides how much of his/her net income to allocate towards current consumption, savings and investments in improving her/his managerial skills. Retirement for managers also occurs exogenously at age $J_{R}$.

We assume that each cohort is $1+n$ bigger than the previous one. These demographic patterns are stationary so that age- $j$ agents are a fraction $\mu_{j}$ of the population at any point in time. The weights are normalized to add up to one, and obey the recursion, $\mu_{j+1}=\mu_{j} /(1+n)$. 
Technology Each manager has access to a span-of-control technology. A plant at date $t$ comprises of a manager with ability $z$ along with labor and capital,

$$
y(t)=A(t) z^{1-\gamma}\left(k^{\alpha} n^{1-\alpha}\right)^{\gamma},
$$

where $\gamma$ is the span-of-control parameter and $\alpha \gamma$ is the share of capital. ${ }^{7}$ The term $A(t)$ is productivity term that is common to all establishments, and given by $A(t)=\bar{A} G_{A}(t)$, where $G_{A}(t)$ grows at the (gross) rate $1+g_{A}$. Thus, $\bar{A}$ controls the level of exogenous productivity.

Every manager can enhance her future skills by investing current income in skill accumulation. The law of motion for managerial skills for a manager who is born at period $t$ is given by

$$
\begin{aligned}
z_{j+1}(t+j) & =\left(1-\delta_{z}\right) z_{j}(t+j-1)+g\left(z_{j}(t+j-1), x_{j}(t+j-1), j\right) \\
& =\left(1-\delta_{z}\right) z_{j}(t+j-1)+B(j) z_{j}(t+j-1)^{\theta_{1}} x_{j}(t+j-1)^{\theta_{2}}
\end{aligned}
$$

where $x_{j}(t)$ is goods invested in skill accumulation by a manager of age $j$ in period $t$. We assume that $\theta_{1} \in(0,1)$ and $\theta_{2} \in(0,1) . B(j)$ is the overall efficiency of investment in skills at age $j$. The skill accumulation technology described above satisfies three important properties, of which the first two follow from the functional form and the last one is an assumption. First, the technology shows complementarities between current ability and investments in next period's ability; i.e. $g_{z x}>0$. Second, $g(z, 0, j)=0$. That is, investments are essential to increase the stock of managerial skills. Finally, since $\theta_{2}<1$, there are diminishing returns to skill investments, i.e. $g_{x x}<0$. Furthermore, we assume that $B(j)=\left(1-\delta_{\theta}\right) B(j-1)$ with $B(1)=\theta$.

\subsection{Decisions}

Let factor prices be denoted by $R(t)$ and $w(t)$ for capital and labor services, respectively. Let $a_{j}(t)$ denote assets at age $j$ and date $t$ that pay the risk-free rate of return $r(t)=R(t)-\delta$.

Managers We assume that there are no borrowing constraints. As a result, factor demands and per-period managerial income (profits) are age-independent, and only depend

\footnotetext{
${ }^{7}$ In referring to production units, we use the terms establishment and plant interchangeably.
} 
on her ability $z$ and factor prices. The income of a manager with ability $z$ at date $t$ is given by

$$
\pi(z, r, w, A, t) \equiv \max _{n, k}\left\{A(t) z^{1-\gamma}\left(k^{\alpha} n^{1-\alpha}\right)^{\gamma}-w(t) n-(r(t)+\delta) k\right\} .
$$

Factor demands are given by

$$
k(z, r, w, A, t)=(A(t)(1-\alpha) \gamma)^{\frac{1}{1-\gamma}}\left(\frac{\alpha}{1-\alpha}\right)^{\frac{1-\gamma(1-\alpha)}{1-\gamma}}\left(\frac{1}{r(t)+\delta}\right)^{\frac{1-\gamma(1-\alpha)}{1-\gamma}}\left(\frac{1}{w(t)}\right)^{\frac{\gamma(1-\alpha)}{1-\gamma}} z
$$

and

$$
n(z, r, w, A, t)=(A(t)(1-\alpha) \gamma)^{\frac{1}{1-\gamma}}\left(\frac{\alpha}{1-\alpha}\right)^{\frac{\alpha \gamma}{1-\gamma}}\left(\frac{1}{r(t)+\delta}\right)^{\frac{\alpha \gamma}{1-\gamma}}\left(\frac{1}{w(t)}\right)^{\frac{1-\alpha \gamma}{1-\gamma}} z
$$

Substituting these into the profit function, one can show that managerial income is given by

$$
\pi(z, r, w, A, t)=A(t)^{\frac{1}{1-\gamma}} \Omega\left(\frac{1}{r(t)+\delta}\right)^{\frac{\alpha \gamma}{1-\gamma}}\left(\frac{1}{w(t)}\right)^{\frac{\gamma(1-\alpha)}{1-\gamma}} z
$$

where $\Omega$ is a constant equal to

$$
\Omega \equiv(1-\alpha)^{\frac{\gamma(1-\alpha)}{(1-\gamma)}} \alpha^{\frac{\gamma \alpha}{(1-\gamma)}}(1-\gamma) \gamma^{\frac{\gamma}{1-\gamma}}
$$

Note that since profits are linear function of managerial ability, $z$, the impact of additional skills on profits is independent of $z$, and a function of parameters, exogenous productivity, and prices only. Also note that given two managers, with ability levels $z$ and $z^{\prime}$, we have

$$
\frac{k\left(z^{\prime}, r, w, A, t\right)}{k(z, r, w, A, t)}=\frac{n\left(z^{\prime}, r, w, A, t\right)}{n(z, r, w, A, t)}=\frac{\pi\left(z^{\prime}, r, w, A, t\right)}{\pi(z, r, w, A, t)}=\frac{z^{\prime}}{z} .
$$

Hence, differences in managerial abilities map one-to-one to differences in establishments sizes and managerial incomes.

The problem of a manager is to maximize (3), subject to

$$
c_{j}(t+j-1)+x_{j}(t+j-1)+a_{j+1}(t+j)=\pi(z, r, w, A, t+j-1)+(1+r(t+j-1)) a_{j}(t+j-1) \quad \forall 1 \leq j \leq J_{R}-1 \text {, }
$$




$$
c_{j}(t+j-1)+a_{j+1}(t+j)=(1+r(t+j-1)) a_{j}(t+j-1) \quad \forall j \geq J_{R},
$$

and

$$
z_{j+1}(t+j)=\left(1-\delta_{z}\right) z_{j}(t+j-1)+B(j) z_{j}(t+j-1)^{\theta_{1}} x_{j}(t+j-1)^{\theta_{2}} \quad \forall 1 \leq j<J_{R}-1,
$$

with $a_{J+1}()=$.0 . The manager chooses consumption at each age, assets and investments in skill formation. For a manager who is born in period $t$ with initial managerial ability $z(t)$, let the value of lifetime discounted utility of being a manager in age 1 be $V(z(t))$.

The solution to the problem of a manager is characterized by two conditions. First, the solution for next-period assets implies a standard Euler equation for asset accumulation

$$
\frac{1}{c_{j}(t+j-1)}=\beta(1+r(t+j)) \frac{1}{c_{j+1}(t+j)}, \quad \forall 1 \leq j<J
$$

Second, the optimality condition for skill investments $(x)$ and (11) imply the following noarbitrage condition for investing in physical capital and skills

$$
\underbrace{(1+r(t+j))}_{\text {marginal cost }}=\underbrace{\pi_{z}(t+j) g_{x}(t+j-1)+\frac{g_{x}(t+j-1)}{g_{x}(t+j)}\left[1+g_{z}(t+j)-\delta_{z}\right]}_{\text {marginal benefit }} \forall 1 \leq j<J_{R}-2,
$$

For age $j=J_{R}-2$, we have

$$
\underbrace{(1+r(t+j))}_{\text {marginal cost }}=\underbrace{\pi_{z}(t+j) g_{x}(t+j-1)}_{\text {marginal benefit }},
$$

The left-hand side of equation (13) is next period's gain in income from one unit of current savings. The manager can also use this one unit as an investment on her skills. Hence, the term $g_{x}($.$) on the right-hand side stands for the additional skills available next period from$ an additional unit of investment in the current period. The term $\pi_{z}($.$) is the additional$ profit generated from an additional unit of managerial skills. Therefore, the right-hand side is the income again captured by the manager in his last working-age from investing one unit of the current consumption good in skill accumulation. It follows that one period before 
retirement, the manager must be indifferent at the margin between investing in assets and skills.

For ages less than $j=J_{R}-2$, the marginal benefit incorporates an additional term as equation (12) shows. This term appears as an extra unit of investment also relaxes the skill accumulation constraint in the subsequent period.

Workers The problem of an age- $j$ worker is to maximize (3) by choice of consumption and assets at each age, subject to

$$
c_{j}(t+j-1)+a_{j+1}(t+j)=w(t+j-1)+(1+r(t+j-1)) a_{j}(t+j-1) \quad \forall 1 \leq j \leq J_{R}-1
$$

and

$$
c_{j}(t+j-1)+a_{j+1}(t+j)=(1+r(t+j-1)) a_{j}(t+j-1) \quad \forall j \geq J_{R},
$$

with $a_{J+1}()=$.0 . Like managers, workers can borrow and lend without any constraint as long as they do not die with negative assets. For an individual born period $t$, let the life-time discounted utility of being a worker at age 1 be given by $W(t)$.

Occupational Choice Let $z^{*}(t)$ be the ability level at which a 1-year old agent is indifferent between being a manager and a worker. This threshold level of $z$ is given by (as agents are born with no assets)

$$
V\left(z^{*}(t)\right)=W(t)
$$

Given all the assumptions made, $V$ is a continuous and a strictly increasing function of $z$. Therefore, (16) has a well-defined solution, $z^{*}(t)$, for all $t$.

\subsection{Balanced Growth}

We focus from now on the balanced growth scenario. In this case, the rate of return to assets and the fraction of managers are constant, and all variables grow in the long run at specified rates, driven ultimately by the two sources of growth in the environment: exogenous productivity growth and exogenous growth in the managerial skills of newborns. In Appendix 2, we show that our economy has a balanced growth path if and only if initial skills growth 
takes place at a given rate. We show therein that the growth rate in output per person $(g)$ along a the balanced growth path is given by

$$
1+g=\left(1+g_{A}\right)^{\psi}
$$

where $\psi$

$$
\psi \equiv \frac{1-\theta_{1}}{\gamma(1-\alpha)+\left(1-\theta_{2}\right)(1-\gamma)-\theta_{1}(1-\alpha \gamma)}
$$

\subsection{Equilibrium}

We outline now what constitutes an equilibrium for an economy in the stationary case, i.e. along a balanced growth path. We normalize variables to account for stationary growth. Define the growth factor $D(t) \equiv(1+g)^{t}$. Hence, we normalize variables wage rates, managerial income, individual consumption, asset holdings and factor demands by $D(t)$, and denote normalized variables by the "^ "symbol (i.e. $\hat{a}_{j}=a_{j}(t) / D(t)$ ). Regarding managerial abilities, recall that managerial ability levels of members of each new cohort are given by $z_{1}(t)=\tilde{z}(t) z$, with a common component that grows over time at the rate $g_{z}$, and a random draw, $z$, distributed with $\operatorname{cdf} F(z)$ and density $f(z)$ on $\left[0, z^{\max }\right]$. Hence, the normalized component is simply $z$ for each individual. After the age-1, and given the stationary threshold value $z^{*}$, the distribution of managerial abilities is endogenous as it depends on investment decisions of managers over their life-cycle.

Let managerial abilities take values in set $\mathcal{Z}=\left[z^{*}, \bar{z}\right]$ with the endogenous upper bound $\bar{z}$. Similarly, let $\mathcal{A}=[0, \bar{a}]$ denote the possible asset levels. Let $\psi_{j}(\hat{a}, z)$ be the mass of age- $j$ agents with assets $\hat{a}$ and skill level $z$. Given $\psi_{j}(\hat{a}, z)$, let

$$
f_{j}(z)=\int \psi_{j}(\hat{a}, z) d \hat{a}
$$

be the skill distribution for age- $j$ agents. Note that $f_{1}(z)=f(z)$ by construction.

Each period those agents whose initial ability is above $z^{*}$ work as managers, whereas the rest are workers. Then, in a stationary equilibrium with given prices, $(r, \hat{w})$, labor, capital and goods markets must clear. The labor market equilibrium condition can be written as

$$
\sum_{j=1}^{J_{R}-1} \mu_{j} \int_{z^{*}}^{\bar{z}} \hat{n}(z, r, \hat{w}, \bar{A}) f_{j}(z) d z=F\left(z^{*}\right) \sum_{j=1}^{J_{R}-1} \mu_{j}
$$


where $\mu_{j}$ is the total mass of cohort $j$. The left-hand side is the labor demand from $J_{R}-1$ different cohorts of managers. A manager with ability level $z$ demands $\hat{n}(z, r, \hat{w}, \bar{A})$ units of labor and there are $f_{j}(z)$ of these agents. The right-hand side is the fraction of each cohort employed as workers. Let $\hat{L}$ denote the size of normalized, aggregate labor in stationary equilibrium.

In the capital market, the demand for capital services must equal the aggregate value of the capital stock. Hence,

$$
\sum_{j=1}^{J_{R}-1} \mu_{j} \int_{z^{*}}^{\bar{z}} \hat{k}(z, r, \hat{w}, \bar{A}) f_{j}(z) d z=\hat{K}
$$

where $\hat{K}$ is the normalized, per person stock of capital and $\hat{k}(z, r, \hat{w}, \bar{A})$ is capital demand from a manager with ability $z$. The goods market equilibrium condition requires that the sum of undepreciated capital stock and aggregate output produced in all plants in the economy is equal to the sum of aggregate consumption and savings across all cohorts plus skill investments by all managers across all cohorts.

Discussion We now discuss a few properties of the model economy that are of importance for our subsequent analysis. First, it is worth noting that managerial investments are essential for the model to reproduce the facts on managerial earnings documented in section 2 . In the absence of investments, initial managerial ability depreciates and managerial earnings would decline over the life cycle. This stands in contrast with the evidence documented for the United States and other countries, where earnings of managers relative to non managers grow substantially with age.

Second, our environment offers a natural notion of aggregate managerial quality, or total managerial skills per manager, $\hat{Z}$. Formally,

$$
\hat{Z} \equiv \frac{\sum_{j=1}^{J_{R}-1} \mu_{j} \int_{z^{*}}^{\bar{z}} z f_{j}(z) d z}{\hat{M}},
$$

where $\hat{M}$ is the number of managers in equilibrium. Hence, changes in managerial quality in response to changes in the environment are determined by changes in the number of managers (i.e. changes in $z^{*}$ ), as well as by changes in the distribution of skills. That is, changes in the incentives to accumulate managerial skills will naturally induce changes in 
managerial quality. Even if the threshold $z^{*}$ in unchanged in response to a change in the environment, the mass of individuals at each level of managerial ability over the life cycle will change as individuals optimally adjust their skill accumulation plans.

Finally, our model of production at heterogenous units aggregates into an production function. It is possible to show that aggregate output can be written as

$$
\hat{Y}=\bar{A} \hat{Z}^{1-\gamma} \hat{M}^{1-\gamma} \hat{K}^{\gamma \alpha} \hat{L}^{\gamma(1-\alpha)}
$$

As we discuss in next sections, changes in occupational decisions across steady-state equilibria affect output in different ways. On the one hand, a reduction in $z^{*}$ raises the number of managers but reduces the size of aggregate labor in equation (20). On the other hand, a reduction in $z^{*}$ reduces the magnitude of managerial quality as defined above since marginal managers are less able than inframarginal ones. As we show next, the resulting managerial quality changes can be quantitatively large in response to policy-induced occupational shifts.

\subsection{Size-Dependent Distortions}

Consider now the stationary environment in which managers face distortions to operate production plants. We model these distortions as size-dependent output taxes. In particular, we assume an establishment with output $y$ faces an average tax rate $T(y)=1-\lambda y^{-\tau}$. This tax function, initially proposed by Benabou (2002), has a very intuitive interpretation: when $\tau=0$, distortions are the same for all establishments and they all face an output tax of $(1-\lambda)$. For $\tau>0$, the distortions are size-dependent, i.e. larger establishments face higher distortions than smaller ones. Hence, $\tau$ controls how dependent on size the distortions are. ${ }^{8}$

With distortions, profits are given by

$$
\pi(z, \hat{r}, \hat{w}, \bar{A})=\max _{n, k}\{\underbrace{\lambda \bar{A}^{1-\tau} z^{(1-\gamma)(1-\tau)}\left(k^{\alpha} n^{1-\alpha}\right)^{\gamma(1-\tau)}}_{\text {after-tax output }}-\hat{w} n-(\hat{r}+\delta) k\}
$$

\footnotetext{
${ }^{8}$ This specification has been recently used by Bauer and Rodriguez-Mora (2014) and Bento and Restuccia (2015) in the development literature. In a public-finance context, this specification has been used by Heathcote, Storesletten and Violante (2014) and Guner, Lopez-Daneri and Ventura (2014), among others, to analyze the effects of income tax progressivity.
} 
From the first order conditions, the factor demands are now given by

$$
\begin{aligned}
n(z, \hat{r}, \hat{w}, \bar{A})= & {\left[\lambda \bar{A}^{1-\tau} \gamma(1-\alpha)(1-\tau)\right]^{\frac{1}{1-\gamma(1-\tau)}} \times } \\
& \times\left(\frac{1}{\hat{r}+\delta}\right)^{\frac{\gamma \alpha(1-\tau)}{1-\gamma(1-\tau)}}\left(\frac{\alpha}{1-\alpha}\right)^{\frac{\gamma \alpha(1-\tau)}{1-\gamma(1-\tau)}}\left(\frac{1}{\hat{w}}\right)^{\frac{1-\gamma \alpha(1-\tau)}{1-\gamma(1-\tau)}} z^{\frac{(1-\gamma)(1-\tau)}{1-\gamma(1-\tau)}},
\end{aligned}
$$

and

$$
\begin{aligned}
k(z, \hat{r}, \hat{w}, \bar{A})= & {\left[\lambda \bar{A}^{1-\tau} \gamma(1-\alpha)(1-\tau)\right]^{\frac{1}{1-\gamma(1-\tau)}} \times } \\
& \times\left(\frac{1}{r+\delta}\right)^{\frac{1-\gamma(1-\alpha)(1-\tau)}{1-\gamma(1-\tau)}}\left(\frac{\alpha}{1-\alpha}\right)^{\frac{1-\gamma(1-\alpha)(1-\tau)}{1-\gamma(1-\tau)}}\left(\frac{1}{\hat{w}}\right)^{\frac{\gamma(1-\alpha)(1-\tau)}{1-\gamma(1-\tau)}} z^{\frac{(1-\gamma)(1-\tau)}{1-\gamma(1-\tau)}} .
\end{aligned}
$$

Using the factor demands 21 and 22 , we can write the profit function as

$$
\pi(z, \hat{r}, \hat{w}, \bar{A})=\left(\lambda \bar{A}^{1-\tau}\right)^{\frac{1}{1-\gamma(1-\tau)}} \widetilde{\Omega}\left(\frac{1}{\hat{r}+\delta}\right)^{\frac{\alpha \gamma}{1-\gamma}}\left(\frac{1}{\hat{w}}\right)^{\frac{\gamma(1-\alpha)}{1-\gamma}} z^{\frac{(1-\gamma)(1-\tau)}{1-\gamma(1-\tau)}}
$$

where

$$
\widetilde{\Omega} \equiv(1-\gamma(1-\tau)) \alpha^{\frac{\gamma \alpha(1-\tau)}{1-\gamma(1-\tau)}}(1-\alpha)^{\frac{\gamma(1-\alpha)(1-\tau)}{1-\gamma(1-\tau)}}(\gamma(1-\tau))^{\frac{\gamma(1-\tau)}{1-\gamma(1-\tau)}}
$$

Note that for any $z$ and $z^{\prime}$, we now have

$$
\frac{k\left(z^{\prime}, \hat{r}, \hat{w}, \bar{A}\right)}{k(z, \hat{r}, \hat{w}, \bar{A})}=\frac{n\left(z^{\prime}, \hat{r}, \hat{w}, \bar{A}\right)}{n(z, \hat{r}, \hat{w}, \bar{A})}=\frac{\pi\left(z^{\prime}, \hat{r}, \hat{w}, \bar{A}\right)}{\pi(z, \hat{r}, \hat{w}, \bar{A})}=\left(\frac{z^{\prime}}{z}\right)^{\frac{(1-\gamma)(1-\tau)}{1-\gamma(1-\tau)}},
$$

where

$$
\frac{(1-\gamma)(1-\tau)}{1-\gamma(1-\tau)}<1
$$

as long as $\tau>0$. That is, for a given distribution of managerial abilities, size-dependent distortions produce a more compressed size distribution of establishments and managerial incomes.

Similarly, for any $z$ and $z^{\prime}$ the optimal skill investment is now characterized by

$$
\frac{x_{j}^{\prime}}{x_{j}}=\left(\frac{z_{j}^{\prime}}{z_{j}}\right)^{\left(\theta_{1}-\frac{\tau}{1-\gamma(1-\tau)}\right) \frac{1}{1-\theta_{2}}} .
$$

It is easy to show that the exponent in the expression is decreasing with respect to the parameter $\tau$ governing size dependency. Hence, size-dependent distortions also reduce incentives of higher-ability managers to invest in their skills. 


\section{Parameter Values}

We assume that the U.S. economy is free of distortions, and calibrate the benchmark model parameters to match aggregate and plant-size moments from U.S. data as well as data on managerial incomes. In particular, we force our economy to reproduce the earnings of managers relative to non-managers over the life cycle estimated in section 2.

For observations on the U.S. plant size data, we use the 2004 U.S. Economic Census. The average plant size is about 17.9, and the distribution of employment across plants is quite skewed. About $72.5 \%$ of plants in the economy employ less than 10 workers, but account for only $15 \%$ of the total employment. On the other hand, less than $2.7 \%$ of plants employ more than 100 employees but account for about $46 \%$ of total employment. From our findings in section 2, managerial incomes (relative to non-managers) grow by about $18 \%$ between ages $25-29$ to $40-44$, and by about $25 \%$ by ages $60-64$.

We assume that the exogenous skill distribution of newborn agents follows a log normal distribution. Specifically, we assume that $\log \left(z_{1}\right)$ is normally distributed with mean normalized to zero $\left(\mu_{z}=0\right)$ and $\sigma_{z}$. We let the model period correspond to 5 years. Each cohort of agents enter the model at age 25 and live until they are 75 years old. Agents retire at age 65. Hence, in the model agents live for 11 model periods; 8 as workers or managers and 3 as retirees.

In our model, the importance of capital $(\alpha)$ and the returns to scale $(\gamma)$, determine the share of capital in output. We determine the values of capital share in output and the depreciation rate from the data. We note that a measure of capital and output consistent with the current model on business plants should include capital and output accounted for by the business sector. The measure of capital and output discussed in Guner et al (2008) is consistent with the current plant size distribution model. Hence, we use the value of capital output ratio and the capital share reported in that paper. These values are 2.325 (at the annual level) and 0.326 , respectively, with a corresponding investment to output ratio of about 0.178 for the period 1960-2000. In line with data, we select the population growth rate such that the annual population growth rate is $1.1 \%$ and the growth rate $(g)$ is $2.6 \%$ a year for our measure of output per worker. Given a capital output ratio and an investment ratio, our (stationary) law of motion of capital implies a depreciation rate of about $4 \%$ at the annual level. 
At the aggregate level, we want the benchmark model to be in consistency with the capital output ratio in the U.S. economy. At the cross sectional level, the model implied distribution of plants should capture some of the important features of the U.S. plant size distribution discussed in the beginning of this section. At the same time, our model should generate age-earning profiles for managers relative to non managers that are consistent with the data. We first proceed to infer the depreciation rate of managerial skills from data of managerial earnings. Since theory predicts no skill investments at the end of the life cycle, we estimate a depreciation rate of skills of about $4.8 \%$ at the annual level. This corresponds to the decline in earnings of managers between ages 55-59 to 60-64 in the data.

We subsequently jointly calibrate the remaining parameters to match the following moments: mean plant size, the fraction of plants with less than 10 workers, the fraction of plants with 100 workers or more, the fraction of the labor force employed in plants with 100 or more employees, the growth of managerial incomes relative to those of non-managers between ages 25-29 and 40-44, the growth of managerial incomes relative to those of nonmanagers between ages 25-29 to 60-64, and the aggregate capital output ratio. Note here that since the capital share in the model is given by $\gamma \alpha$, and since this value has to be equal to the data counterpart ( 0.326), a calibrated value for $\gamma$ determines $\alpha$ as well. The resulting parameter values are displayed in Table 1 . Table 2 shows the targeted moments together with their model counterparts as well as the entire plant size distribution.

Skill Investments In our calibration, the fraction of resources that are invested in skill accumulation is of about 1\% of GDP. Despite the relatively small fraction of resources devoted to the improvement of managerial skills, the incomes of managers grow significantly with age in line with data. Figure 12 shows that the earnings of managers relative to non managers in the model are in conformity with the data. It is important to emphasize that managerial skill investments play a central role in this case. If we halve the value of the parameter $\theta_{2}$ that governs incentives to invest goods in skill formation, we find that while resources invested in skill formation drop to about $0.6 \%$ of output, the relative earnings growth of managers to non managers in prime years $(\hat{g})$ drops from the benchmark value of 0.252 to 0.106 .

It is also important to mention that benchmark model is able to replicate properties of the entire plant size distribution fairly well, as demonstrated in Table 2 . In particular, the 
model is able to generate concentration of employment in very large plants. Again, skill accumulation plays an important role in this case. We calculate that if we give managers the skills they are born with for their entire life cycle (i.e. skill formation is not allowed), mean plant size drops from 17.7 to about 15.7, and the share of employment accounted by large plants (100 employees and higher) drops from $46 \%$ to about $37.8 \%$. In similar fashion, if we alternatively halve the value of $\theta_{2}$ as above, this share drops to $36.2 \%$ and mean size drops also to about 15.7 employees.

\section{Findings}

In this section, we present and discuss the central quantitative findings of the paper. We first explore the implied responses of our model economy to variations in economy-wide productivity. Subsequently, we introduce distortions as described in section 3.4 and quantify their importance. Finally, we evaluate the relative importance of each channel in accounting for differences in relative earnings growth and output across countries.

\subsection{Variation in Economy-wide Productivity}

We now consider the effects of changes in economy-wide productivity levels; the term $\bar{A}$ that is common to all establishments. Two main reasons motivate our exercises. First, it is of interest to understand the extent to which variation in economy-wide productivity can affect variation in relative earnings growth across countries. If variation in this variable can account for observed output gaps across countries, can it also account for observed differences in the life-cycle earnings growth of managers relative to non managers? Second, there is substantial variation in the size of establishments across countries that is correlated to the level of development. ${ }^{9}$ If productivity differences affect the accumulation of managerial skills, they can also contribute to cross-country differences in establishment size.

Table 3 shows our results when we lower economy-wide productivity, or productivity for short, relative to the benchmark economy across steady states. We consider three levels of productivity alongside the benchmark value; $\bar{A}=\{0.9,0.8,0.7\}$. Not surprisingly, exogenous reductions in productivity lead to substantial reductions in output across steady states.

\footnotetext{
${ }^{9}$ The size of production establishments is strongly associated with output levels across countries. Bhattacharya (2010) documents such differences in establishment size for selected countries. Bento and Restuccia (2015) uncover large size differences between rich and poor countries in the manufacturing sector.
} 
When $\bar{A}$ is lowered by $10 \%, 20 \%$ and $30 \%$, output declines by about $15.5 \%, 29.8 \%$ and $43.1 \%$, respectively. This follows from the standard effects of lower productivity across the board, in conjunction with the lower accumulation of managerial skills over the life cycle emphasized here. In this regard, Table 3 shows that investment in managerial skills drop from about $0.9 \%$ of output to about $0.6 \%$ when economy-wide productivity drops by $30 \%$.

As a result of lower investment in managerial skills, relative age-earnings profiles become flatter as Table 3 demonstrates. A reduction in economy-wide productivity of $20 \%$ translates into a reduction of more than half in the earnings growth of managers relative to non managers. Relative earnings growth can even turn negative for low values of economy-wide productivity. Therefore, the model has the potential to generate the positive relation between GDP per worker and the steepness of age-earnings profiles documented in section 2 (see Figure 2).

It is worth relating these results to properties of standard span-of-control models. First, managerial skills are simply endowments in models of that class. Thus, in a life-cycle context, such models cannot account for the relative earnings facts documented in section 2. Second, the same forces that lead to changes in the steepness of relative managerial profiles lead also to equilibrium changes in plant size. Changes in exogenous productivity, as modeled here, do not generate size differences in a growth model with a Lucas (1978) span-of-control technology, as changing $\bar{A}$ has no effect on occupational decisions. ${ }^{10}$ The consequences of changing aggregate productivity, however, are different in the current setup. As productivity drops, both wage rates and managerial rents drop as in the standard span-of-control model. But a productivity drop also reduces the marginal benefit associated to an extra unit of income invested in skill accumulation (see equations 12 and 13). As a result, managerial skills become overall lower, which translates into further reductions in labor demand and therefore, on the wage rate. The net result is a reduction in the value of becoming a worker relative to a manager at the start of life, which leads in turn to an increase in the number of managers. Quantitatively, however, these size effects are moderate as Table 3 demonstrates.

Finally, Table 3 shows that aggregate managerial quality drops alongside reductions in economy-wide productivity: a reduction in $\bar{A}$ of $30 \%$ translates into a reduction in managerial quality of more than $15 \%$. Again, this occurs due to the presence of investments in managerial

\footnotetext{
${ }^{10}$ This requires a Cobb-Douglas specification as we assume in this paper.
} 
skills. Lower managerial quality follows from the (small) increase in the number of managers across steady states, in conjunction with lower investments in managerial skills in response to a reduction in economy-wide productivity - see equation (19).

Output and Earnings Growth Differences Given the results in Table 3, it is natural to ask the extent to which the model can reproduce the relation between GDP per worker and the relative earnings growth for managers that we observe in the data. To this end, for each of the countries in our data, we select a value of $\bar{A}$ such that our model economy reproduces GDP per worker of that country relative to the U.S. We keep all other parameters fixed at their benchmark values.

We find that the model predicts a weaker relationship between output and the relative earnings growth of managers over the life cycle than it is observed in the data. While in the data the elasticity between the log of these variables is about 0.57 , our model predicts a value of about 0.39 . In other words, there is more variation in relative earnings growth in the data that what our model predicts exclusively via changes in economy-wide productivity. Output changes driven by changes in economy-wide productivity are not accompanied, however, by corresponding reductions in relative earnings growth as observed in the data. As a result, the variance in $\log (\hat{g})$ implied by the model is just about $11 \%$ of the variance of this variable in the data.

\subsection{Size-Dependent Distortions}

We now study the quantitative role of size-dependent distortions via the implicit tax function $T(y)=1-\lambda y^{-\tau}$, as explained in section 3.4. The key in this formulation is the curvature parameter $\tau$ governing the degree of size dependency; if $\tau>0$, the plants with higher output levels face higher marginal and average rates, while if $\tau=0$, implicit taxes are the same for all, regardless of the level of output.

We evaluate the consequences across steady states of an array of values for the parameter $\tau$ in Table 4 , under $\lambda=1$. For each value of $\tau$, Table 4 also reports the implied tax wedge, measured as the take home rate, $1-T(y)$, evaluated at the 5 times the mean output. As Table 4 demonstrates, the effects of size-dependent distortions can be dramatic on some variables. Introducing size-dependent distortions leads to a reduction in output across steady states, an increase in the number of managers (reduction of plant size), and to a reallocation of 
output and employment to smaller production units. In the context of the current setup, these effects are concomitant with less investment in managerial skills and thus, with less steep age-earnings profiles of managers relative to non-managers. This occurs as with the introduction of distortions that are size dependent, large establishments reduce their demand for capital and labor services relatively more than smaller ones, leading to a reduction in the wage rate. This prompts the emergence of smaller production units, as individuals with low initial managerial ability become managers. This is the mechanism highlighted in Guner et al (2008) and others. In addition, investment in skills decline in the current setup reinforcing the equilibrium effects on output, size and managerial quality.

The Quantitative Importance of Distortions How large are the distortions imposed by different levels of $\tau$ ? To answer this question, we calculate the distortions borne by large plants at high multiples of mean output levels relative to those at mean output. ${ }^{11}$ From this perspective, we find that distortions do not increase too much with output. For instance, the distorting factor at five times mean output amounts to 0.97, 0.94, and 0.91, for values of $\tau$ of $0.02,0.04$ and 0.06 , respectively. That is, in all cases the distorting factors differ by less than ten percentage points.

Quantitatively, rising size dependency from zero to $\tau=0.02$ leads to a reduction in output of about $7.1 \%$, a reduction in mean size from 17.7 to 13.2 employees, and to a sizable reduction in managerial quality of about $26.7 \%$. The effect on the relative earnings growth of managers is substantial, with a reduction in the slope coefficient $(\hat{g})$ to more than half the benchmark value. Indeed, as Table 4 shows, it is possible to eliminate all growth in relative managerial earnings over the life cycle! A value of $\tau=0.06$ leads to a negative slope coefficient. Such change is accompanied by a drop in output of about $18.7 \%$, and by a drastic reduction in managerial quality of about $54.4 \%$.

It is worth noting that the concentration of employment at large establishments drops significantly with distortions. About $46 \%$ of employment is accounted for by plants with 100 employees or more in the benchmark economy. This figure drops sharply as the size dependency of distortions becomes more important. At $\tau=0.02$, the share of employment

\footnotetext{
${ }^{11}$ Specifically, we calculate the ratio of one minus the marginal rate on plants at $k$ times mean output relative to mean output. Since the marginal tax rate amounts to $(1-\tau) \lambda y^{-\tau}$, this ratio effectively amounts to $k^{-\tau}$.
} 
in large establishments is $34 \%$ while at $\tau=0.06$, this variable falls to less than half of its benchmark value. The behavior of the employment at large establishments in response to distortions, like other key variables, is closely connected to the importance of skill investments for our findings. We quantify the role of skill investments for our findings in section 6 .

How do our findings relate to data presented in section 2? Table 4 shows that a level of distortions associated to $\tau=0.02$ leads to a decline in the relative earnings growth of managers comparable to the level of Italy, as documented in section 2. Italy's gap in terms of output per worker is of about $12 \%$ in relation to the United States in the data. Thus, from this perspective, size-dependent distortions alone can account for more than half of Italy's output gap (7\% vs. 12\%). Overall, size-dependent distortions can generate substantial reductions in the relative earnings growth of managers and can also lead to sizable output losses.

\section{Discussion}

We present below two set of exercises to highlight the quantitative role of different aspects of our model. First, we investigate the extent to which transitions between managerial and nonmanagerial work matter for our quantitative results. Second, we evaluate the quantitative importance of investments in managerial skills.

\subsection{Occupational Transitions over the Life Cycle}

We have so far considered a model abstraction where each individual chooses his/her occupation, whether to be a worker or a manager, at the start of his/her life and this decision is irreversible. Thus, our abstraction assumes away potential transitions between non-managerial and managerial work. We ask: is this omission quantitatively important?

To address this question, we first document facts on transitions between managerial and non-managerial occupations in U.S. data. We subsequently build and calibrate a model economy that allows agents to switch between occupations, and evaluate whether our conclusions on the effects of exogenous productivity changes and distortions are robust to occupational switches. We present this analysis in detail in Appendix III.

We find that as the result of occupational switches, the fraction of managers grows in the first half of the life cycle, and then remains roughly constant until retirement. Nonetheless, 
our model - parameterized to capture the changes in the number of managers over the life cycle - predicts that the effects of exogenous productivity changes and distortions on the variables of interest is remarkably similar to the effects we found under the simpler benchmark model benchmark. We then conclude that for the questions addressed in this paper, a richer model that accommodates transitions between managerial and non-managerial occupations is not essential.

\subsection{The Importance of Skill Investments}

We now attempt to quantify the importance of the novel channel emphasized in this paper - managerial skill investments - for a host of variables of interest. We ask: how large is the amplification role of such investments in response to size-dependent distortions and exogenous reductions in productivity? We answer this question via two different variations of our model economy. We first consider the case when managerial investments are not allowed, but individuals are endowed with the same age-profile managerial skills over the life cycle as in the benchmark economy. We dub this scenario Fixed Lifetime Skills. In the second case, skill investments are also shut down but individuals are endowed with their skill endowment at each age. We dub this scenario Fixed Initial Skills. ${ }^{12}$ We concentrate our analysis in two special values of distortions and productivity; $\tau=0.02$ and $\bar{A}=0.9$. These values are about the average values in our cross-country analysis in section 7 .

Distortions Our findings are summarized in Table 5 for key variables; output, mean size, managerial quality and the employment share in large $(100+)$ establishments. We find that managerial skill formation accounts for about one fourth (24-27\%) of changes in output when size-dependent distortions are introduced. This is a significant finding, for investments in skill formation are less than $1 \%$ of output in the benchmark economy.

For size statistics, the message is somewhat different; managerial skill formation accounts for a smaller fraction of the changes predicted by the benchmark model when distortions are introduced. For mean size, skill formation accounts for about $9 \%$ of the changes under fixed lifetime skills and nearly 19\% under the fixed initial skills scenario. For the share of employment at large establishments, skill formation accounts for about $24 \%$ of the changes

\footnotetext{
${ }^{12}$ For each scenario, we compute a steady state in the absence of distortions and under $\bar{A}=1$. We use these steady states as the basis for our quantification of the importance of skill investments.
} 
under fixed lifetime skills and nearly $15 \%$ under the fixed initial skills scenario. All these suggest that the economic forces behind a standard span-of-control model tend to dominate for predicted changes in size statistics.

We find that skill formation has a substantial role upon the predicted changes in managerial quality. Table 5 indicates that about $25 \%-35 \%$ of changes in this variable can be accounted for by changes in the skills of managers across steady states. In understanding this finding, recall from our discussion in section 3.3 that changes in this variable is affected by the number of managers across steady states as well as by changes in the skill distribution of managers. Thus, while there are large changes in the number of managers due to size-dependent distortions, the ensuing changes in the incentives to accumulate skills lead to substantial effects on managerial quality.

Economy-wide Productivity Unlike the findings for distortions, the contribution of managerial skill formation to changes in output driven by productivity changes is relatively small (between $6 \%$ and $8 \%$ ). Thus, the bulk of changes in this variable across steady states in this case are due to standard forces; the direct impact of changes in productivity on output plus the indirect effects via capital accumulation.

For the rest of the variables in Table 5, our analysis establishes that managerial skill formation accounts for all changes across steady states. This is expected. As mentioned earlier, under a span-of-control model with exogenous managerial skills, exogenous changes in productivity lead to no changes in the plant-size distribution and therefore, on managerial quality. Hence, it follows that any change in these variables in response to productivity changes is driven by the associated changes in managerial skills.

\section{Accounting for Cross-Country Differences}

We investigated in previous sections the extent to which exogenous variation in productivity and in size-dependent distortions affect several variables of interest. We now concentrate on the role of these two exogenous sources of variation for the facts documented in section 2. We ask: what is contribution of cross-country differences in exogenous productivity versus distortions in accounting for differences in output per worker and relative earnings growth? To answer this question, we perform a straightforward exercise. We select values 
for productivity $(\bar{A})$ and distortions $(\tau)$ for each country to reproduce (i) output per worker levels, and (ii) relative earnings growth $(\hat{g})$. That is, we select parameters to reproduce, as well as we can, the position of each country in Figure $2 .{ }^{13}$ We then eliminate each of the cross-country differences separately, and evaluate the quantitative role of each source of cross-country variation.

Consider first differences in $\bar{A}$, i.e. keep $\bar{A}$ at its calibrated value for each country and set $\tau=0$. Figure 13 shows the model-implied and the actual relation between GDP per worker and the relative earnings growth of managers. In line with our previous findings, we find that when we only allow for differences in $\bar{A}$, the model predicts a weaker relationship between output and the relative earnings growth of managers over the life cycle. In particular, while variation in $\bar{A}$ is able to generate significant differences in output per worker, the variation in relative earnings growth is more muted than in the data. As a result, while in the data the elasticity between the log of these variables is about 0.57 , our model predicts a value of about 0.39 - around the same value as in section 5.1.

Turning into the role of distortions, what happens if we keep $\tau$ at its calibrated value for each country and set $\bar{A}=1$ ? Figure 14 shows the results of this exercise. The elasticity between log of relative earnings growth and log of GDP per worker is now about 0.96, much higher than the elasticity in the data (0.57). That is, in contrast to the case of variation in $\bar{A}$, the model predicts a stronger relationship between log-output per worker and $\hat{g}$ than in the data. Indeed, the correlation between data and model-implied output relative earnings growth is about 0.90 . In other words, we find that size-dependent distortions are critical to generate the observed variation in cross-country relative earnings growth of managers.

This exercise allows us to calculate the GDP per worker gap between each country and the U.S. that can be accounted by differences in $\bar{A}$ and $\tau$. To this end, we compute GDP per worker in the model when keeping $\tau$ at its calibrated values and setting $\bar{A}=1$ (the U.S. value), and then calculate the implied output gap with the US and compare it with the same gap in the data. These calculations, for example, imply that about $43 \%$ of the output gap between Italy and the U.S. can be accounted for by differences in $\tau$. For Sweden, the equivalent figure is $18 \%$. Repeating the same exercise for other countries, we find that

\footnotetext{
${ }^{13}$ In Figure 2, relative earnings growth for managers is negative for four countries (Finland, Iceland, Spain and Denmark). The model has difficulty to generate negative relative earnings growth observed in the data. The calibration exercise, nonetheless, is able to match the remaining 16 countries exactly.
} 
differences in distortions account on average for about $42 \%$ of the output per worker gaps with the U.S. in our data. The rest is accounted by differences in economy-wide productivity and interaction effects.

\section{Concluding Remarks}

We document that across a group of high-income countries, the mean earnings of managers tend to grow faster than for non managers over the life cycle, and that the earnings growth of managers relative to non managers over the life cycle is positively correlated with output per worker. We develop an equilibrium, span-of-control model to interpret these facts in which managers invest in their skills. Thus, the incentives of managers to invest in their skills are central in determining the growth of their earnings over the life cycle. As a result, our model predicts endogenous differences in managerial quality across countries driven by selection - who becomes a manager - and by investments in managerial skills. We discipline this model with a host of observations on managerial earnings, the size-distribution of plants in the United States and macroeconomic aggregates.

We introduce and quantify the importance of aggregate productivity differences, and sizedependent distortions as emphasized by the misallocation literature. We find that distortions that halve the growth of relative managerial earnings over the life cycle the hypothetical case of Italy in our data reduce output by $7 \%$. This is about half of the observed output gap between the US and Italy.

Our findings also show that distortions are responsible for the bulk of differences in the relative earnings growth of managers over the life cycle across countries in our data. As a result, observations on relative earnings growth can be used as natural targets to discipline the level of distortions. In a decomposition exercise, we find that cross-country variation in distortions - estimated to create observed cross-country differences in relative earnings growth - can account for about $42 \%$ of the cross-country variation in output per worker with the U.S. 


\section{References}

[1] Akcigit, Ufuk, Alp, Harun and Micheal Peters. 2014. "Lack of Selection and Imperfect Managerial Contracts: Firm Dynamics in Developing Countries." mimeo.

[2] Alder, Simeon D. 2015. "In the Wrong Hands: Complementarities, Resources Allocation, and TFP." Forthcoming, American Economic Journal: Macroeconomics.

[3] Atkeson, Andrew and Ariel Burstein, 2011. "Aggregate Implications of Innovation Policy." mimeo.

[4] Atkeson, Andrew and Ariel Burstein. 2010. "Innovation, Firm dynamics, and International Trade". Journal of Political Economy, vol. 118(3): 433-484

[5] Bartelsman, Eric John Haltiwanger, and Stefano Scarpetta. 2103. "Cross-country Differences in Productivity: The Role of Allocation and Selection." American Economic Review, 103(1): 305-34.

[6] Bauer, Christian and Jose V. Rocriguez Mora. 2014. "The Joint Determination of TFP and Financial Sector Size." mimeo.

[7] Benabou, Rolland. 2002. "Tax and Education Policy in a Heterogeneous-Agent Economy: What Levels of Redistribution Maximize Growth and Efficiency?" Econometrica 70(2): 481-517.

[8] Bento, Pedro and Diego Restuccia. 2015. "Misallocation, Establishment Size, and Productivity." Mimeo.

[9] Bhattacharya, Dhritiman, Guner, Nezih and Gustavo Ventura. 2013. "Distortions, Endogenous Managerial skills and Productivity Differences." Review of Economic Dynamics, 16(1): 11-25.

[10] Bhattacharya, Dhritiman. 2010. "The Size Distribution of Plants and Economic Development." Unpublished Ph.D. dissertation, The University of Iowa.

[11] Bloom, Nicholas and John Van Reenen. 2011. "Human Resource Management and Productivity." In Handbook of Labor Economics, ed. David Card and Orley Ashenfelter, Amsterdam: Elsevier. 
[12] Bloom, Nicholas, Genakos, Christos, Sadun, Raffaella and John Van Reenen. "Management Practices across Firms and Countries." Academy of Management Perspectives 26(1): $12-33$.

[13] Bloom, Nicholas, Sadun, Raffaella and John Van Reenen. 2014. "Management as a Technology." mimeo.

[14] Bloom, Nicholas, Lemos, Renata, Sadun, Raffaella, Scur, Daniela and John Van Reenen. 2014. "The New Empirical Economics of Management." Journal of the European Economic Association, 12(4): 835-876.

[15] Buera, Francisco J., Joseph P. Kaboski, and Yongseok Shin. 2011. "Finance and Development: A Tale of Two Sectors." American Economic Review 101(5): 1964-2002.

[16] Caliendo, Lorenzo and Esteban Rossi-Hansberg. 2012. "The Impact of Trade on Organization and Productivity." The Quarterly Journal of Economics 127(3): 1393-1467.

[17] Caselli, Francesco. 2005 "Accounting for Cross-Country Income Differences," in Handbook of Economic Growth, ed. Philippe Aghion and Steven N. Durlauf, Amsterdam:Elsevier.

[18] Caselli, Francesco, and Nicola Gennaioli. 2013. "Dynastic Management." Economic Inquiry, 51(1): 971-996.

[19] Celik, Murat Alp. 2015. "Does the Cream Always Rise to the Top? The Misallocation of Talent and Innovation." Mimeo.

[20] Cole, Harold, Greenwood, Jeremy and Juan M. Sanchez. 2012. "Why Doesn't Technology Flow from Rich to Poor Countries?" Working Paper 2012-040A, Federal Reserve Bank of St Louis.

[21] Cubas, Germán, Ravikumar, B. and Gustavo Ventura. 2013. "Talent, Labor Quality and Economic Development." Forthcoming, Review of Economic Dynamics.

[22] Deaton, Angus. 1997. The Analysis of Household Surveys: A Microeconometric Approach to Development Policy. Washington, DC: World Bank Publications. 
[23] Establishment and Enterprise Census, Statistics Japan.

[24] Erosa, Andrés, Koreshkova, Tatyana and Diego Restuccia. 2010. "How Important is Human Capital? A Quantitative Theory Assessment of World Income Inequality," Review of Economic Studies 77 (4): 1421-49.

[25] European Union Statistics on Income and Living Conditions (EU-SILC). 2004-2012.

[26] Gabler, Alain and Markus Poschke. 2013. "Experimentation by Firms, Distortions, and Aggregate Productivity" Review of Economic Dynamics 16(1): 26-38.

[27] Garcia-Santana, Manuel and Roberto Ramos. 2015. "Distortions and the Size Distribution of Plants: Evidence from Cross-Country Data." SERIEs (the Journal of the Spanish Economic Association) 6 (3): 79-312.

[28] Garcia-Santana, Manuel and Josep Pijoan-Mas. 2014. "The Reservation Laws in India and the Misallocation of Production Factors." forthcoming Journal of Monetary Economics.

[29] Garicano, Luis, Lelarge, Claire, and John Van Reenen. 2013. "Firm Size Distortions and the Productivity Distribution: Evidence from France." IZA DP no. 7241.

[30] Guner, Nezih, Ventura, Gustavo and Yi Xu. 2006. "How Costly Are Restrictions on Size?", Japan and the World Economy 18(3): 203-320.

[31] Guner, Nezih, Ventura, Gustavo and Yi Xu. 2008. "Macroeconomic Implications of Size-Dependent Policies." Review of Economic Dynamics 11(4): 721-744.

[32] Gennaioli, Nicola, La Porta, Rafael, Lopez-de-Silanes, Florencio and Andrei Shleifer. 2013. "Human Capital and Regional Development." The Quarterly Journal of Economics. 128 (1): 105-164.

[33] Guner, Nezih, Lopez-Daneri, Martin and Gustavo Ventura. 2015. "Heterogeneity and Government Revenues: Higher Taxes at the Top?" mimeo.

[34] Hall, Robert E., and Charles I. Jones. 1999. "Why Do Some Countries Produce So Much More Output per Worker than Others?" Quarterly Journal of Economics 114(1): $83-116$. 
[35] Heathcote, J., Storesletten, J. and G. L. Violante. "Optimal Tax Progressivity: An Analytical Framework." Mimeo, 2014.

[36] Hopenhayn, Hugo. A. 2014. "Firms, Misallocation and Aggregate Productivity: A Review." Annual Review of Economics 6: 735-770.

[37] Hsieh, Chang-Tai, and Peter Klenow. 2009. "Misallocation and Manufacturing TFP in China and India." Quarterly Journal of Economics 124(4): 1403-1448.

[38] Hsieh, Chang-Tai and Peter Klenow. 2012. "The Life Cycle of Plants in India and Mexico." mimeo.

[39] Jones, Charles I. and Jihee Kim. 2014. "A Schumpeterian Model of Top Income Inequality." mimeo.

[40] Klenow, Peter J., and Andres Rodriguez-Clare. 1997. "The Neoclassical Revival in Growth Economics: Has it Gone Too Far?" In Macroeconomics Annual 1997. , ed. Ben S. Bernanke and Julio J. Rotemberg, 73-102. Cambridge:MIT Press.

[41] Lagakos, David, Moll, Benjamin, Porzio, Tommaso and Nancy Qian. 2013. "Experience Matters: Human Capital and Development Accounting." mimeo.

[42] Lucas, Jr., Robert E. 1978. "On the Size Distribution of Business Firms." Bell Journal of Economics, 9(2): 508-523.

[43] Luxembourg Income Study (LIS) Database, http://www.lisdatacenter.org (multiple countries; microdata accessed from November 2013 to February 2015). Luxembourg: LIS.

[44] Manuelli, Rodolfo and Ananth Seshadri. 2014. "Human Capital and the Wealth of Nations." American Economic Review 104(9): 2736-62.

[45] Midrigan, Virgiliu and Yi Xu . 2010. "Finance and Misallocation: Evidence from Plantlevel Data." American Economic Review, 104(2): 422-58.

[46] Minnesota Population Center. 2014. Integrated Public Use Microdata Series, International: Version 6.3 [Machine-readable database]. Minneapolis: University of Minnesota. 
[47] Prescott, Edward. 1998. "Needed: A Theory of Total Factor Productivity." International Economic Review, 39(3): 525-551.

[48] Restuccia, Diego. 2013. "Factor Misallocation and Development," The New Palgrave Dictionary of Economics, Online Edition, Eds. Steven N. Durlauf and Lawrence E. Blume, Palgrave Macmillan.

[49] Restuccia, Diego, and Richard Rogerson. 2008. "Policy Distortions and Aggregate Productivity with Heterogeneous Establishments." Review of Economic Dynamics, 11(4): $707-720$.

[50] Restuccia, Diego, and Richard Rogerson. 2013. "Misalloaction and Productivity." Review of Economic Dynamics, 16(1): 1-10.

[51] Roys, Nicolas and Ananth Seshadri. 2013. " Economic Development and the Organization of Production." mimeo.

[52] Rubini, Loris. 2011. "Innovation and the Elasticity of Trade Volumes to Tariff Reductions." mimeo.

[53] Ruggles, Steven, J. Trent Alexander, Katie Genadek, Ronald Goeken, Matthew B. Schroeder, and Matthew Sobek. 2010. Integrated Public Use Microdata Series: Version 5.0 [Machine-readable database]. Minneapolis: University of Minnesota. 
Table 1: Parameter Values (annualized)

\begin{tabular}{lc}
\hline \hline Parameter & $\frac{\text { values }}{0.011}$ \\
Population Growth Rate $(n)$ & 0.025 \\
Productivity Growth Rate $(g)$ & 0.040 \\
Depreciation Rate $(\delta)$ & 0.423 \\
\hline Importance of Capital $(\alpha)$ & 0.77 \\
Returns to Scale $(\gamma)$ & 0 \\
Mean Log-managerial Ability $\left(\mu_{z}\right)$ & 2.875 \\
Dispersion in Log-managerial Ability $\left(\sigma_{z}\right)$ & 0.944 \\
Discount Factor $(\beta)$ & 0.881 \\
Skill accumulation technology $(\theta)$ & 0.053 \\
Skill accumulation technology $\left(\delta_{\theta}\right)$ & 0.68 \\
Skill accumulation technology $\left(\theta_{1}\right)$ & 0.49 \\
Skill accumulation technology $\left(\theta_{2}\right)$ & 0.048 \\
Skill accumulation technology $\left(\delta_{z}\right)$ & \\
\hline \hline
\end{tabular}

Note: Entries show model parameters calibrated for the benchmark economy. See text for details.

Table 2: Empirical Targets: Model and Data

\begin{tabular}{|c|c|c|}
\hline$\underline{\text { Statistic }}$ & $\underline{\underline{\text { Data }}}$ & $\underline{\underline{\text { Model }}}$ \\
\hline Mean Size & 17.9 & 17.7 \\
\hline Capital Output Ratio & 2.32 & 2.31 \\
\hline Managerial Income (40-44/25-29) & 1.18 & 1.18 \\
\hline Managerial Income (60-64/25-29) & 1.25 & 1.24 \\
\hline \multicolumn{3}{|l|}{ Fraction of Establishments } \\
\hline 1-9 workers & 0.725 & 0.726 \\
\hline 10-20 workers & 0.126 & 0.128 \\
\hline $20-50$ workers & 0.091 & 0.085 \\
\hline 50-100 workers & 0.032 & 0.031 \\
\hline $100+$ workers & 0.026 & 0.030 \\
\hline \multicolumn{3}{|l|}{ Employment Share } \\
\hline 1-9 workers & 0.151 & 0.172 \\
\hline 10-20 workers & 0.094 & 0.100 \\
\hline $20-50$ workers & 0.164 & 0.148 \\
\hline 50-100 workers & 0.128 & 0.121 \\
\hline $100+$ workers & 0.462 & 0.459 \\
\hline
\end{tabular}

Note: Entries show the empirical targets used in the quantitative analysis and the model's performance. The fraction of establishments with 1-9 and 100+ workers, and the employment share with $100+$ workers are explicit targets. See text for details. 
Table 3: Effects of Economy-Wide Productivity

\begin{tabular}{lcccc}
\hline \hline Economy-Wide Productivity & $\bar{A}=1$ & $\bar{A}=0.9$ & $\bar{A}=0.8$ & $\bar{A}=0.7$ \\
\hline Statistic & & & & \\
Output & 100 & 84.5 & 70.2 & 56.9 \\
Mean Size & 17.7 & 17.2 & 17.0 & 16.0 \\
Investment in Skills & 100 & 73.3 & 52.1 & 35.3 \\
Investment in Skills (\% Output) & 0.92 & 0.80 & 0.68 & 0.57 \\
Number of Managers & 100 & 102.9 & 102.9 & 105.8 \\
Managerial Quality & 100 & 93.6 & 90.1 & 84.6 \\
Employment Share (100+) & 0.46 & 0.45 & 0.44 & 0.43 \\
Relative Earnings Growth $(\hat{g})$ & 0.22 & 0.16 & 0.11 & 0.05 \\
\hline \hline
\end{tabular}

Note: Entries show the effects on displayed variables associated to exogenous reductions in the level of economy-wide productivity $(\bar{A})$ across steady states. Column 2 report benchmark values $(\bar{A}=1)$. Column 3-5 report the changes emerging from reducing $\bar{A}$ below the benchmark value. See text for details.

Table 4: Effects of Size-Dependent Distortions

\begin{tabular}{lccccc}
\hline \hline Size Dependency $(\tau)$ & 0 & 0.02 & 0.04 & 0.06 & 0.08 \\
Tax Wedge $\left(\frac{1-T(5 \bar{y})}{1-T(y)}\right)$ & 1 & 0.97 & 0.94 & 0.91 & 0.88 \\
\hline & & & & & \\
Statistic & 100.0 & 92.9 & 86.7 & 81.3 & 76.2 \\
Output & 17.7 & 13.2 & 10.2 & 8.2 & 6.8 \\
Mean Size & 100.0 & 62.1 & 41.6 & 29.6 & 22.1 \\
Investment in Skills & 0.92 & 0.61 & 0.44 & 0.33 & 0.27 \\
Investment in Skills (\% Output) & 100.0 & 131.9 & 166.9 & 203.4 & 239.8 \\
Number of Managers & 100.0 & 73.2 & 56.6 & 45.6 & 38.2 \\
Managerial Quality & 0.46 & 0.34 & 0.25 & 0.17 & 0.11 \\
Employment Share (100+) $(\hat{g})$ & 0.22 & 0.09 & 0.02 & -0.02 & -0.05 \\
Relative Earnings Growth
\end{tabular}

Note: Entries show the effects on displayed variables associated to size-dependent distortions across steady states. Column 2 report benchmark values. Column 3-6 report the changes emerging from increasing the size dependency of distortions. See text for details. 
Table 5: The Role of Managerial Skill Formation (\%)

\begin{tabular}{|c|c|c|c|c|}
\hline \multirow[t]{2}{*}{$\underline{\text { Statistic }}$} & \multicolumn{2}{|c|}{$\underline{\text { Fixed Lifetime Skills }}$} & \multicolumn{2}{|c|}{ Fixed Initial Skills } \\
\hline & $\overline{\tau=0.0}$ & $\bar{A}=0.9$ & $\tau=0.02$ & $\overline{\bar{A}=0.9}$ \\
\hline Output & 23.8 & 7.6 & 27.0 & 6.6 \\
\hline Mean Size & 8.6 & 100.0 & 18.6 & 100.0 \\
\hline Managerial Quality & 24.7 & 100.0 & 34.8 & 100.0 \\
\hline Employment Share $100+$ & 23.6 & 100.0 & 14.8 & 100.0 \\
\hline
\end{tabular}

Note: Entries show the percentage contribution of managerial skill formation for selected variables in response to the introduction of distortions of $\tau=0.02$, and a reduction in economy-wide productivity to $\bar{A}=0.9$. The case of 'Fixed Lifetime Skills' assumes that the age-profile of manager's skills does is unchanged relative to the benchmark economy. The case of 'Fixed Initial Skills' assumes that manager's skills at any age are given by the endowments at birth. See text for details. 


\section{Appendix I: Data on Managerial Incomes}

Table A1: Data Sources

\begin{tabular}{|c|c|c|c|}
\hline Country & $\underline{\underline{\text { Years }}}$ & $\underline{\underline{\text { Source }}}$ & No. of Obs. \\
\hline Australia & $1995,2001,2003,2008,2010$ & LIS (Survey of Income and Housing Costs) & 34,202 \\
\hline Austria & 2004-2012 & EU-SILC & 44,426 \\
\hline Belgium & 2004-2011 & EU-SILC & 37,231 \\
\hline Canada & $1981,1991,2001$ & IPUMS-International (Canadian Census) & 652,124 \\
\hline Denmark & 2004-2012 & EU-SILC & 59,241 \\
\hline Finland & 2004-2010, 2012 & EU-SILC & 97,390 \\
\hline France & 2004-2007, 2009-2010, 2012 & EU-SILC & 65,423 \\
\hline Germany & $2005-2012$ & EU-SILC & 76,978 \\
\hline Iceland & 2004-2010, 2012 & EU-SILC & 30,181 \\
\hline Ireland & $2004-2010$ & EU-SILC & 24,015 \\
\hline Israel & $2001,2005,2007,2010$ & LIS (Household Expenditure Survey) & 22,316 \\
\hline Italy & 2007-2010, 2012 & EU-SILC & 89,420 \\
\hline Luxembourg & 2004-2010, 2012 & EU-SILC & 32,105 \\
\hline Netherlands & 2005-2010, 2012 & EU-SILC & 58,233 \\
\hline Norway & 2004-2010, 2012 & EU-SILC & 49,038 \\
\hline Spain & $2006-2012$ & EU-SILC & 77,196 \\
\hline Sweden & 2004-2010, 2012 & EU-SILC & 53,589 \\
\hline Switzerland & $2011-2012$ & EU-SILC & 13,105 \\
\hline UK & 2005-2010, 2012 & EU-SILC & 47,197 \\
\hline US & $1990,2000,2005,2010$ & IPUMS (US Census and ACS) & $10,928,272$ \\
\hline
\end{tabular}


Table A2: Managerial Occupations

Australia

Before 2001, International Standard Classification of Occupations (ISCO-88), Codes 11-13

Legislators, senior officials and managers

Corporate managers

Managers of small enterprises

After 2001, ASCO, occupation code 1

Managers and administrators

Austria, Belgium, Canada, Denmark, Finland, France, Germany, Iceland, Ireland Israel, Italy, Luxembourg, Netherlands, Norway, Spain, Sweden, Switzerland, UK

International Standard Classification of Occupations (ISCO-88), Codes 11-13

Legislators, senior officials and managers

Corporate managers

Managers of small enterprises

$\underline{\mathrm{US}}$

IPUMS-USA 1990 Occupation Codes 004-022

Chief executives and public administrators, Financial managers,

Human resources and labor relations managers, Managers and Specialists in marketing, advertising, and public relations, Managers in education and related fields, Managers of medicine and health occupations, Postmasters and mail superintendents, Managers of food services and lodging occupations, Managers of properties and real estate, Funeral directors, Managers of service organizations, Managers and administrators 


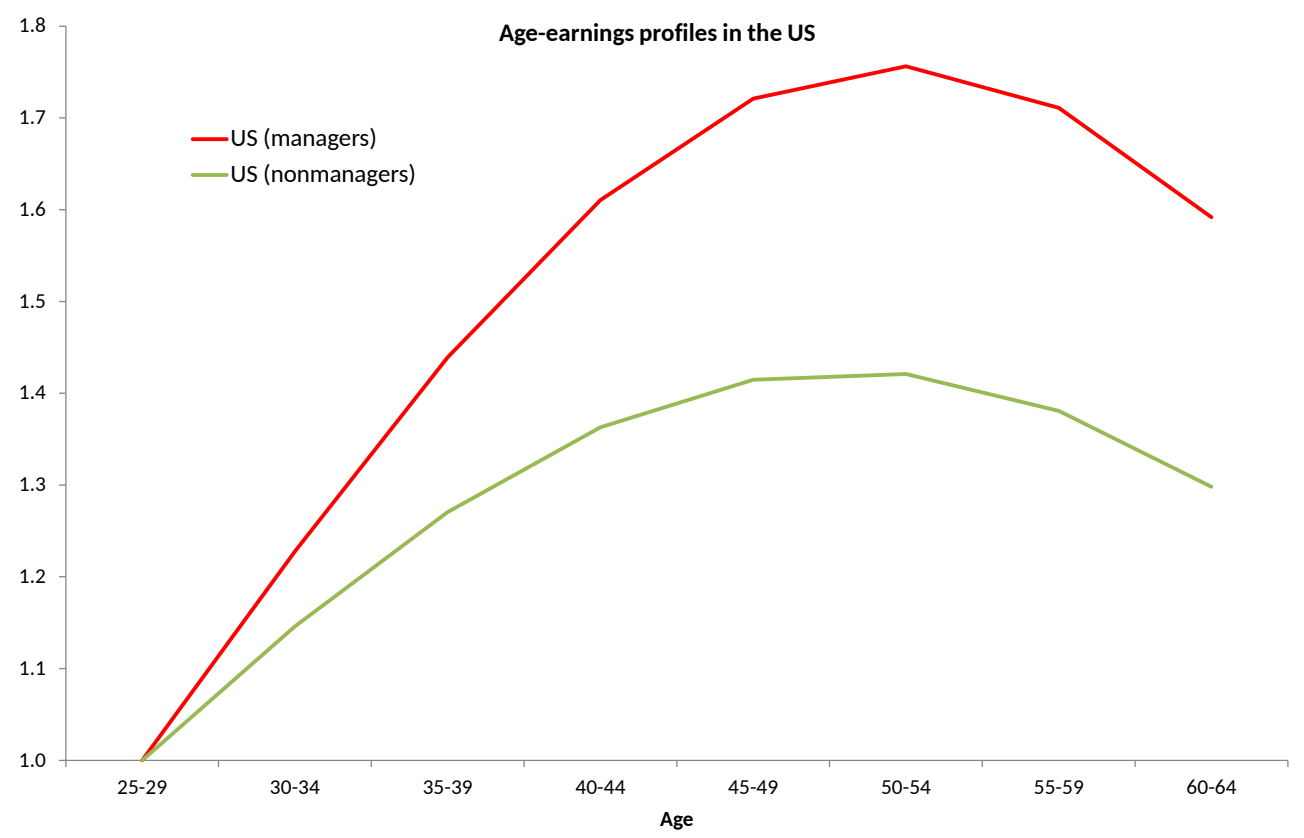

Figure 1

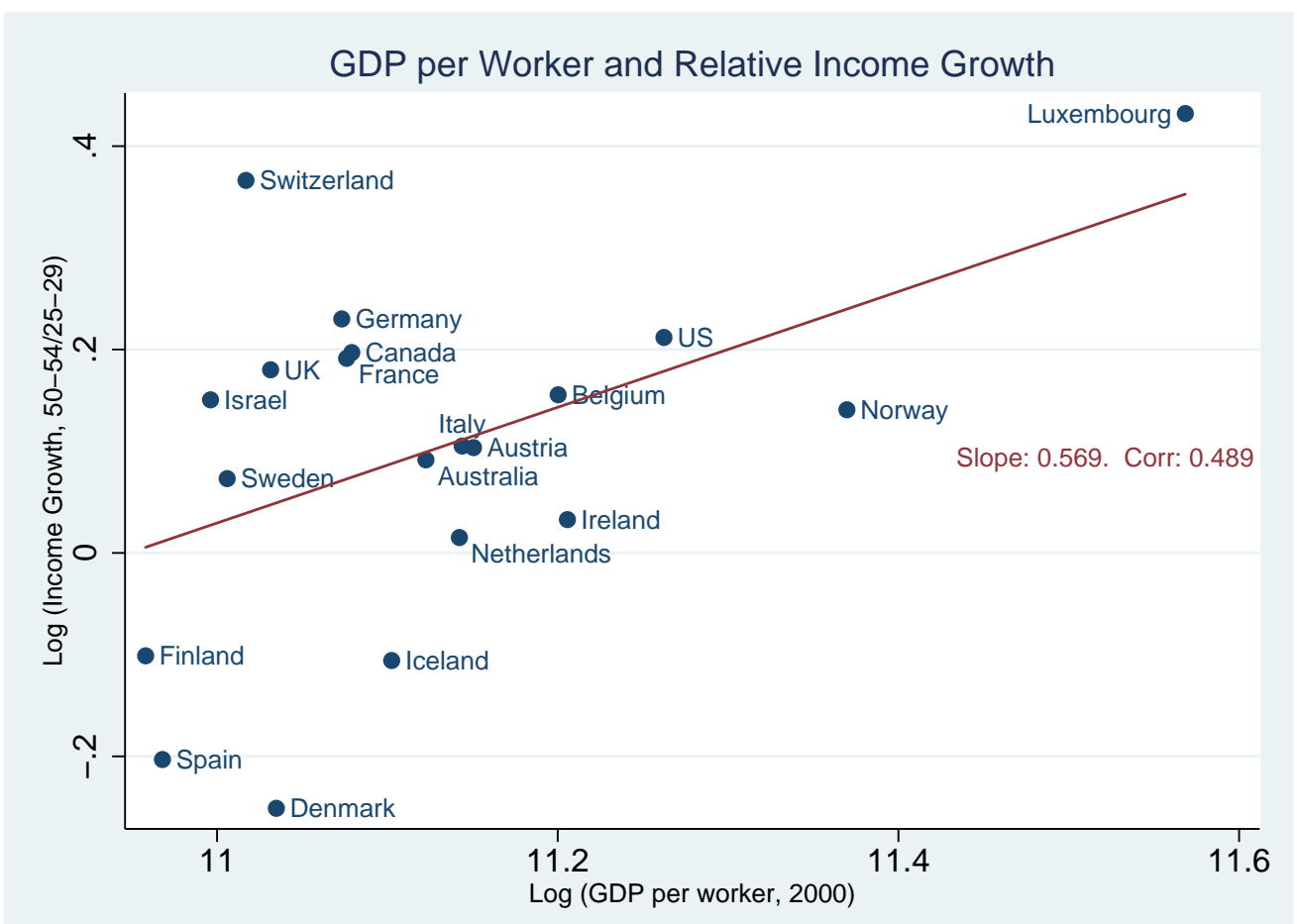

Figure 2 


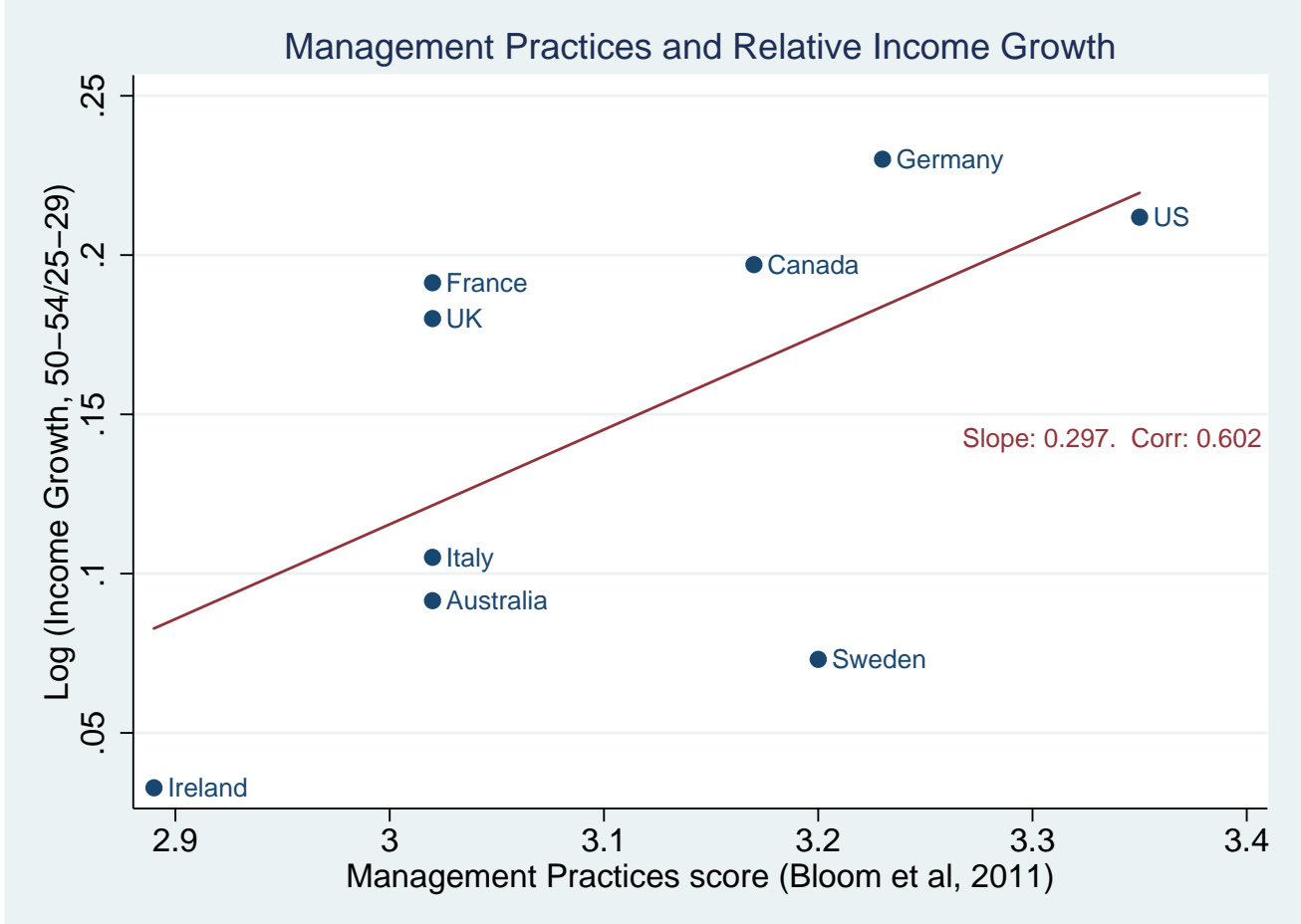

Figure 3

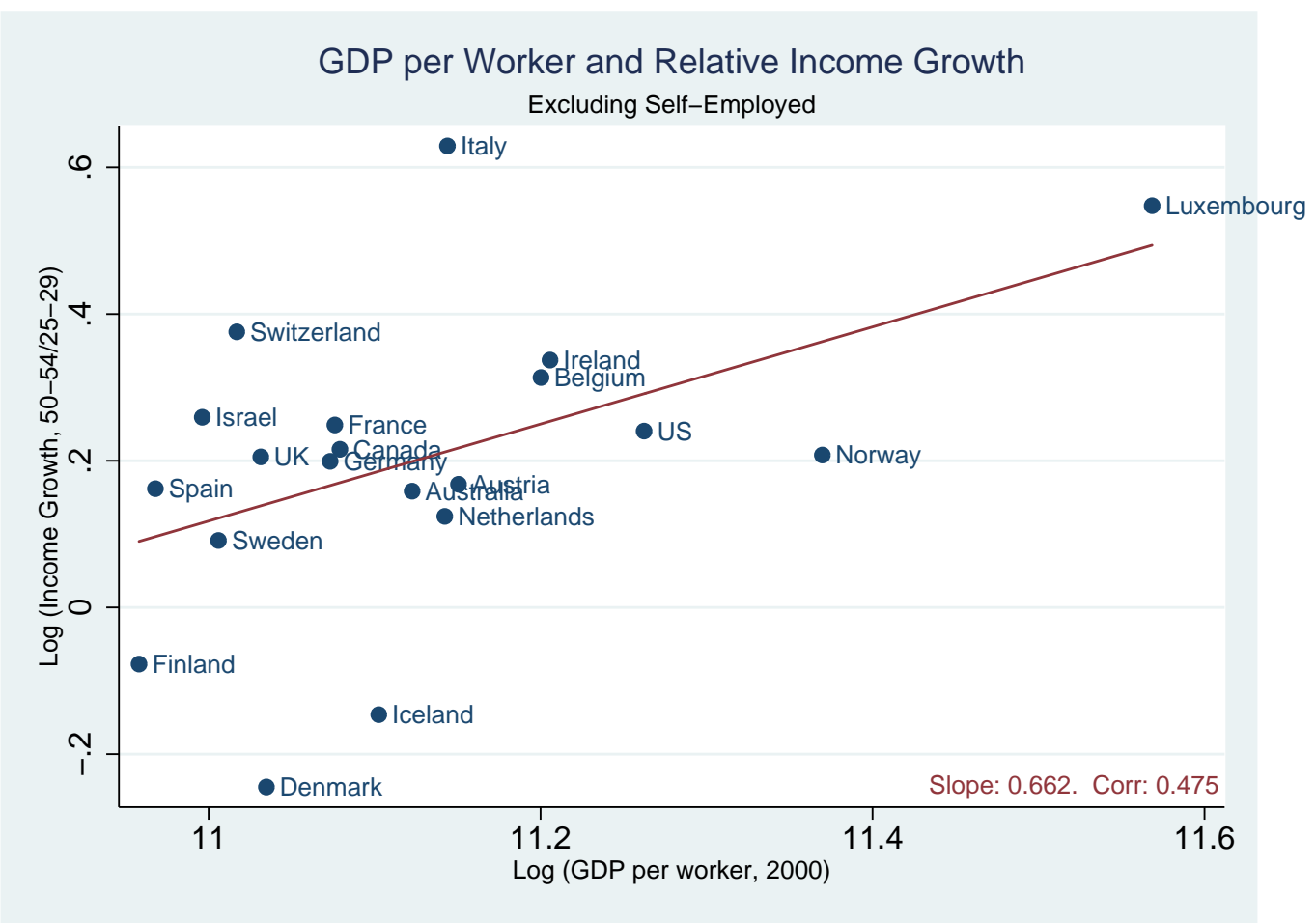

Figure 4 


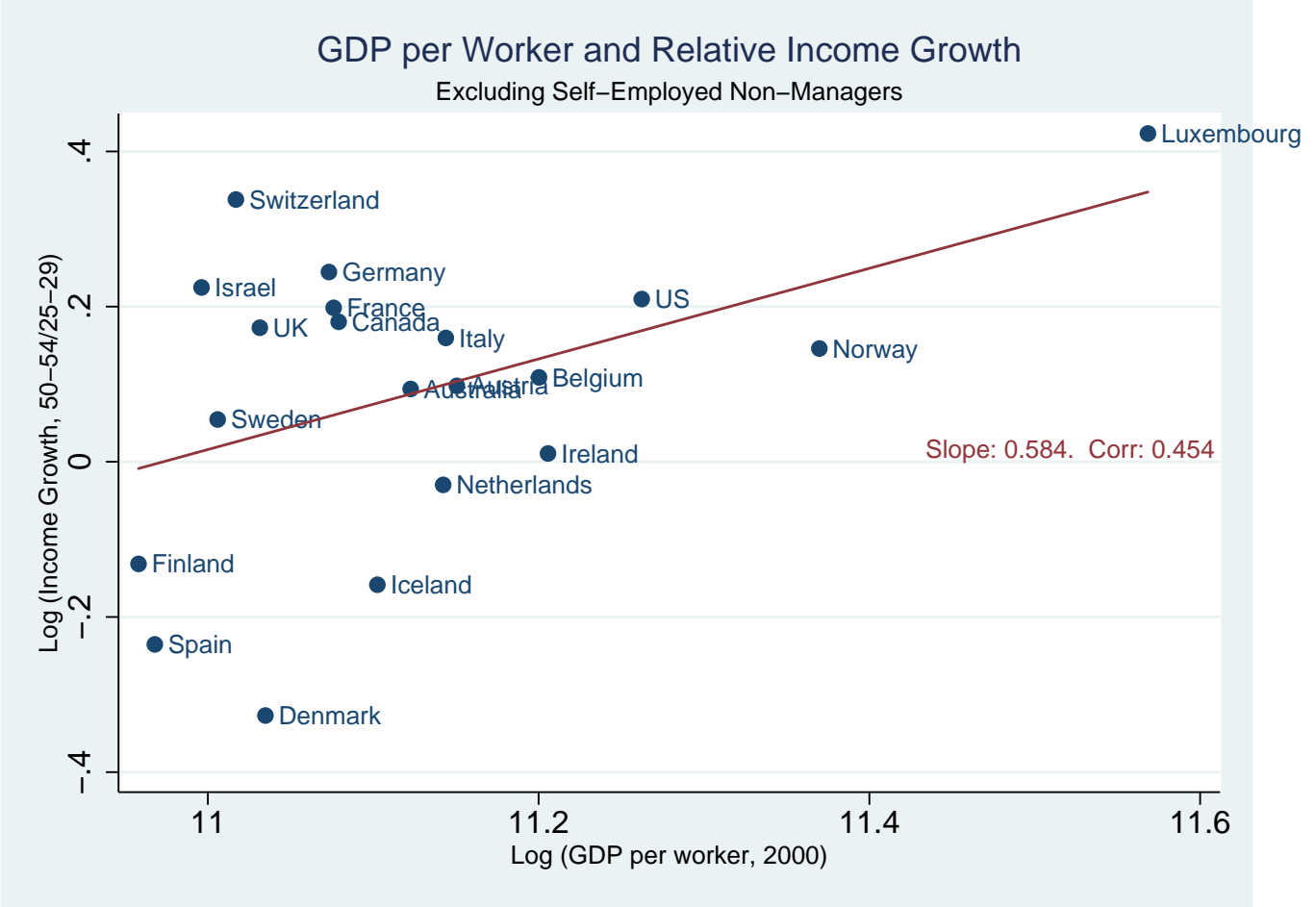

Figure 5

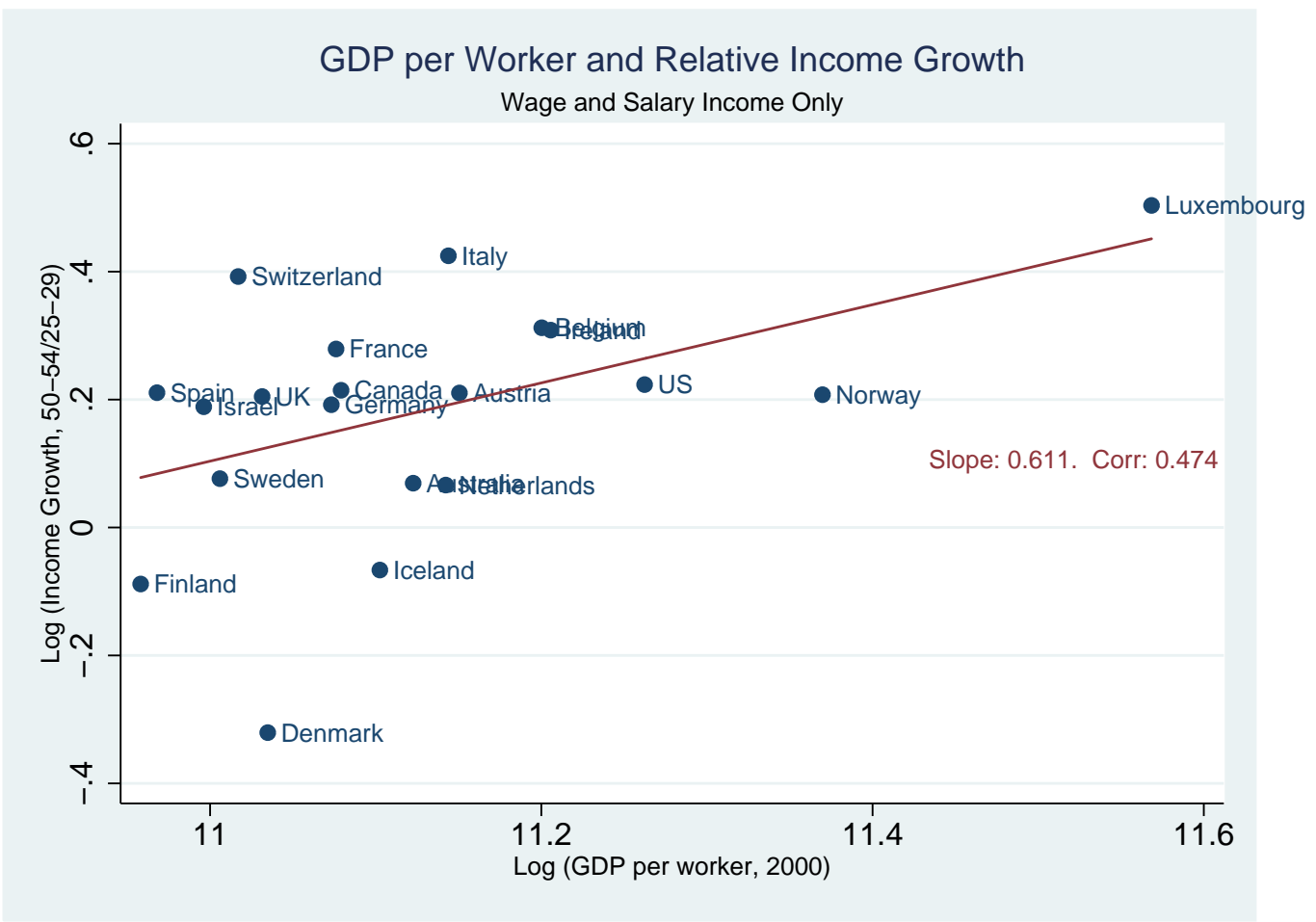

Figure 6 


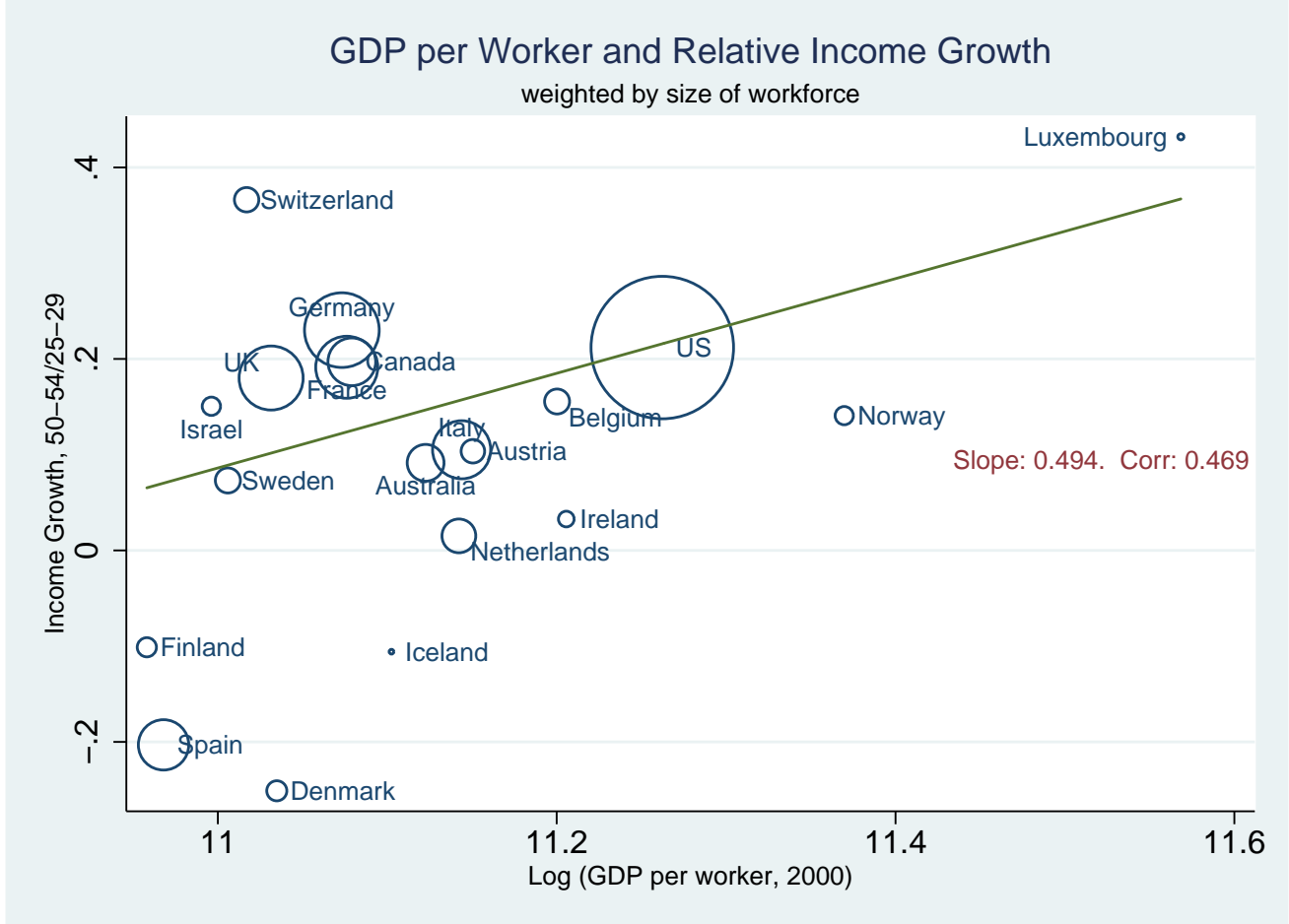

Figure 7

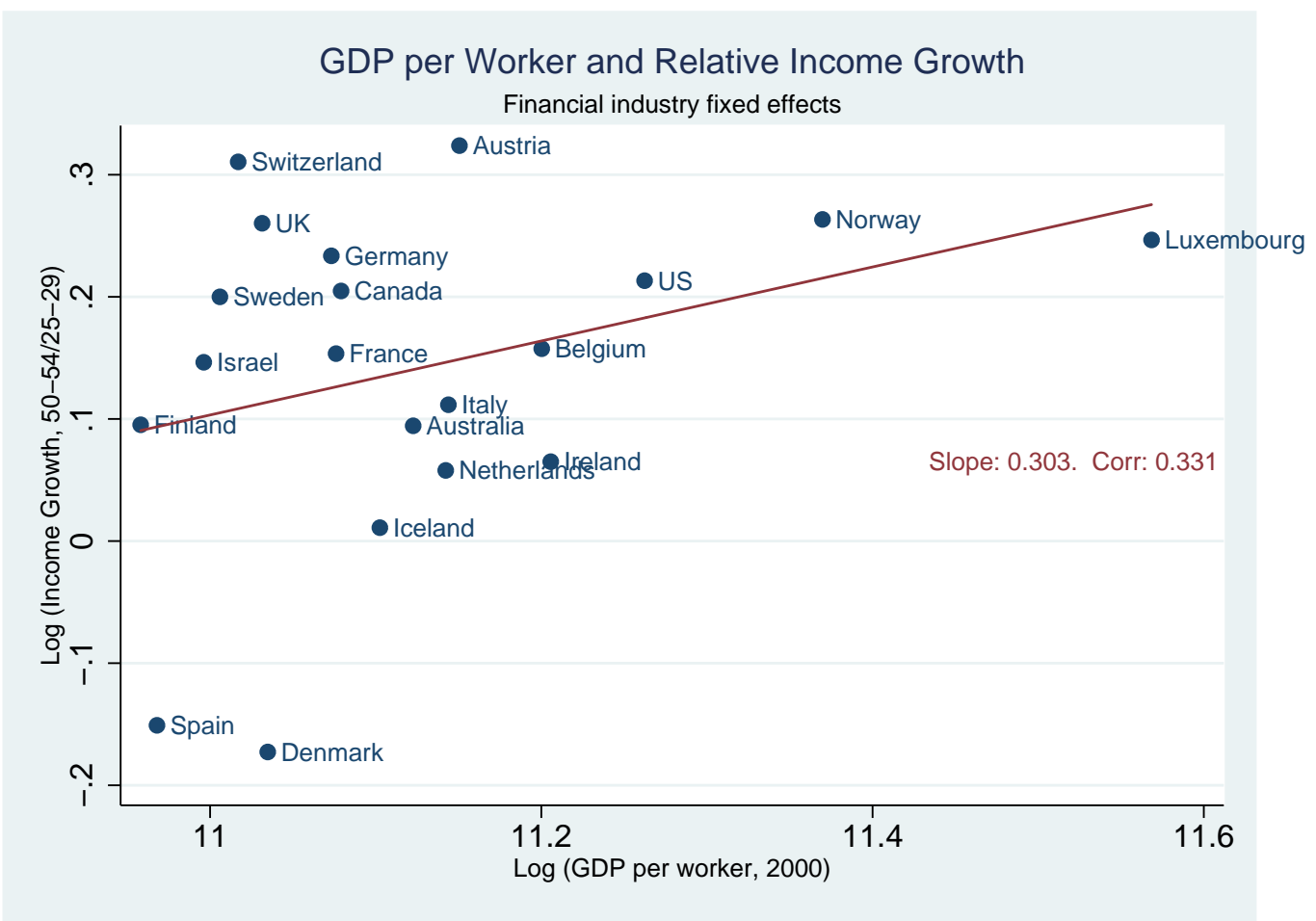

Figure 8 


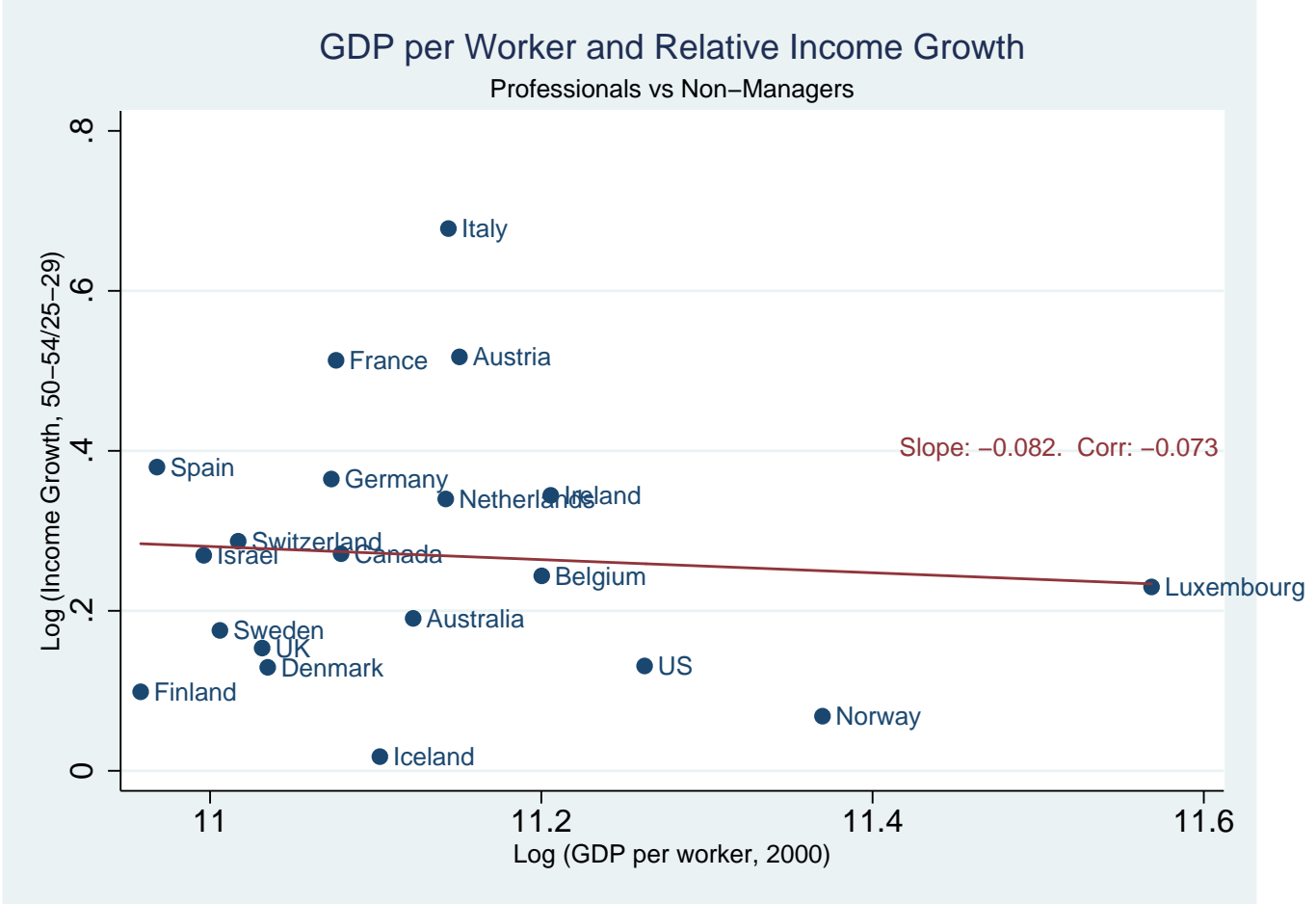

Figure 9

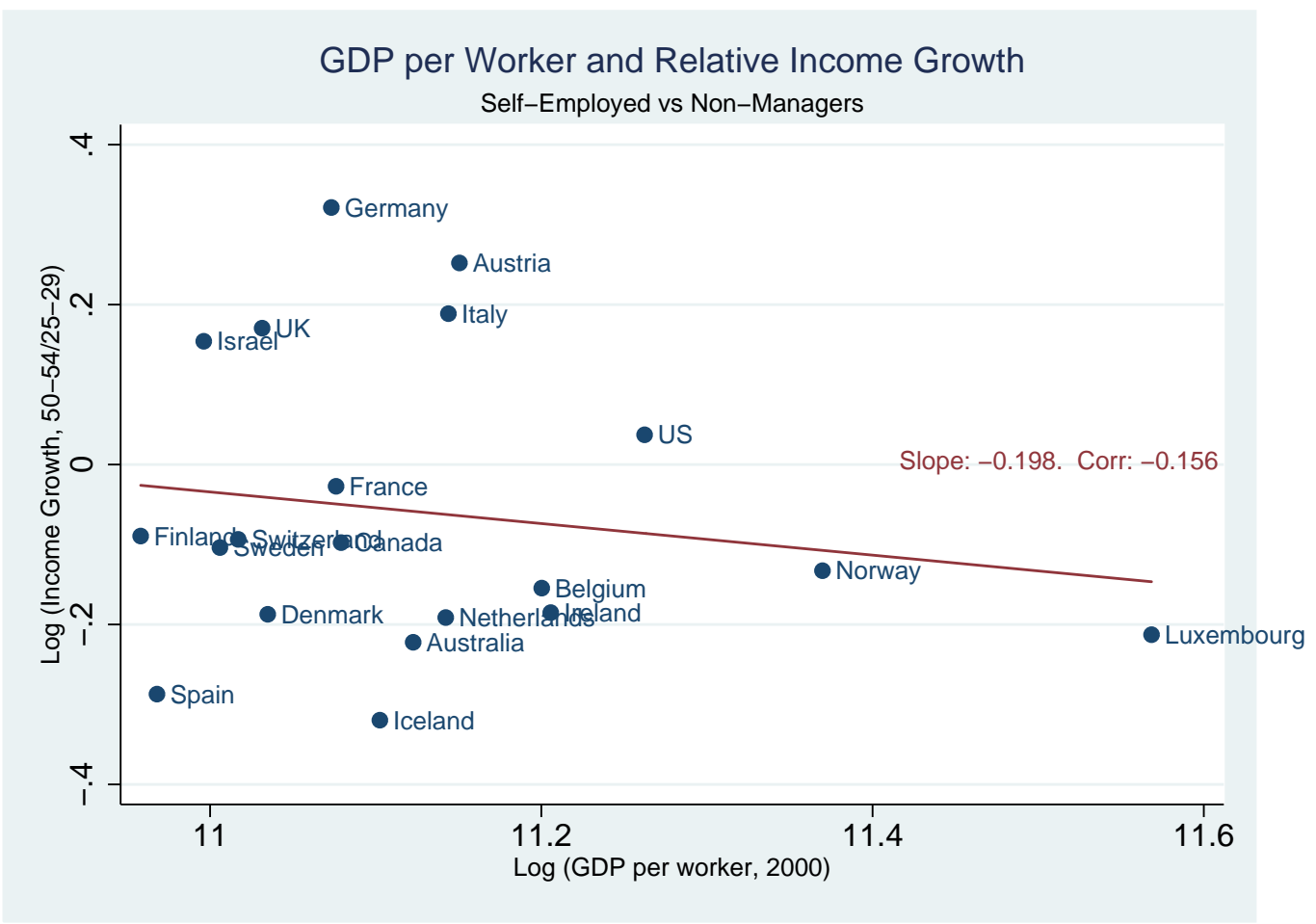

Figure 10 


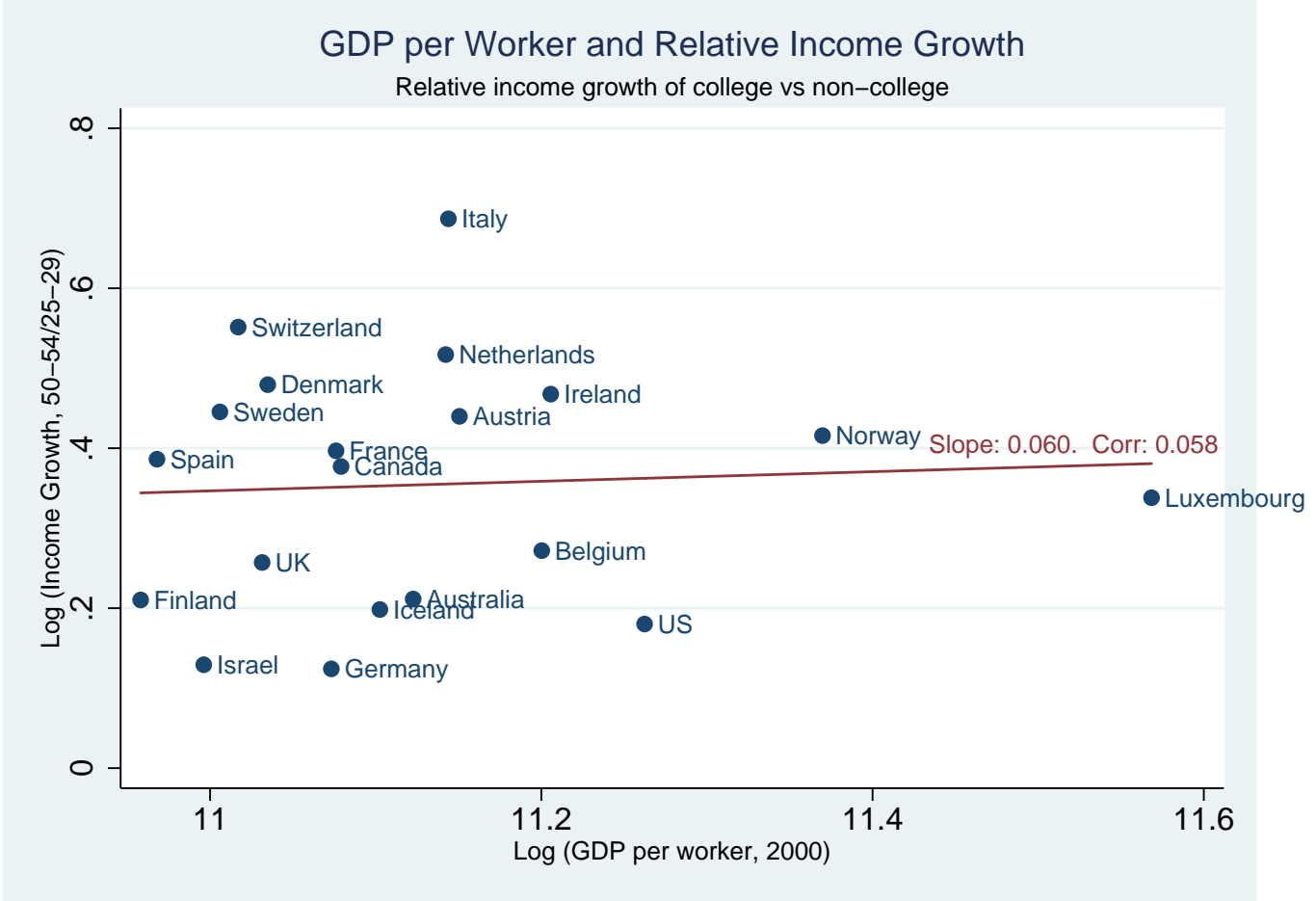

Figure 11

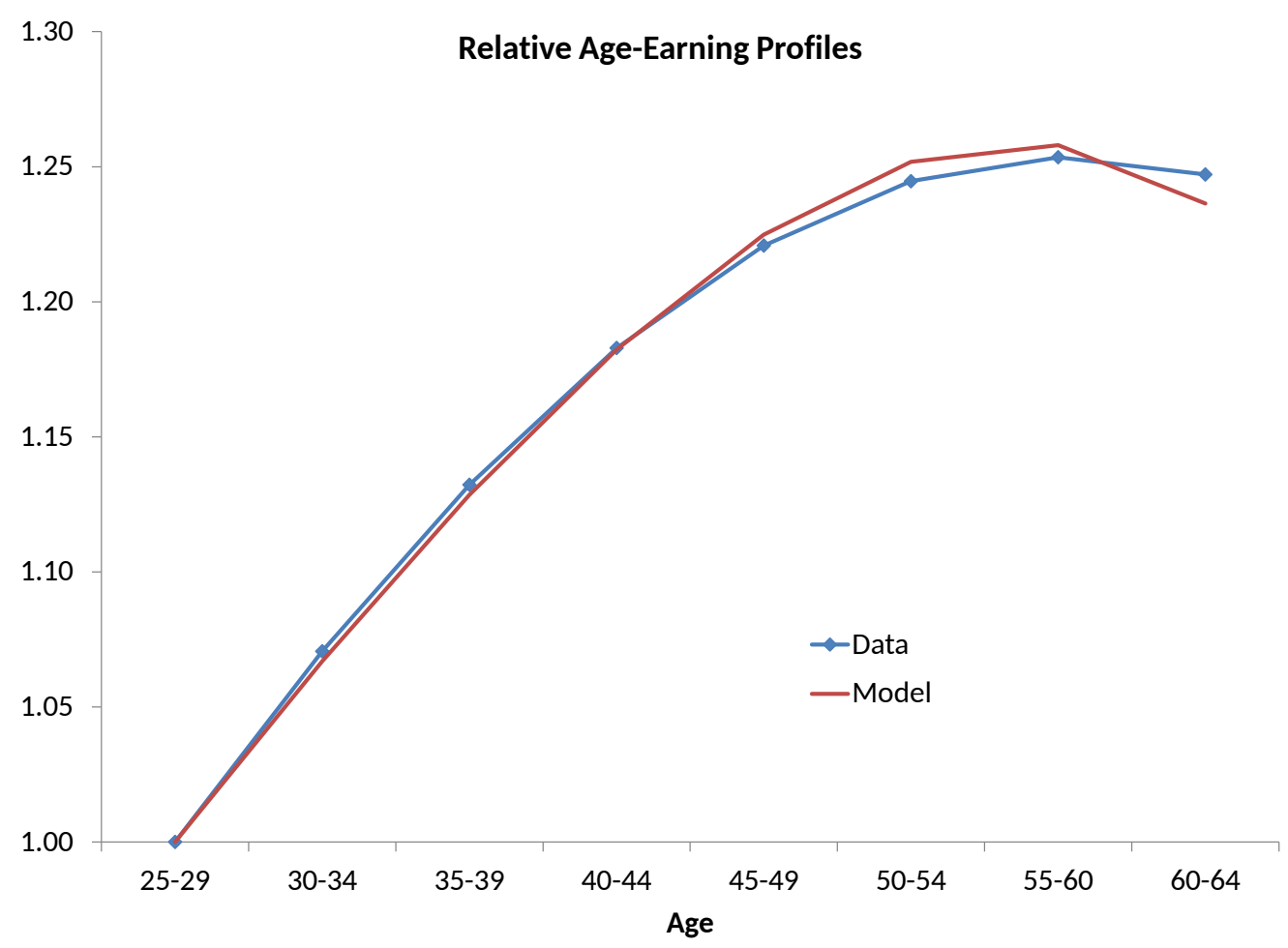

Figure 12 


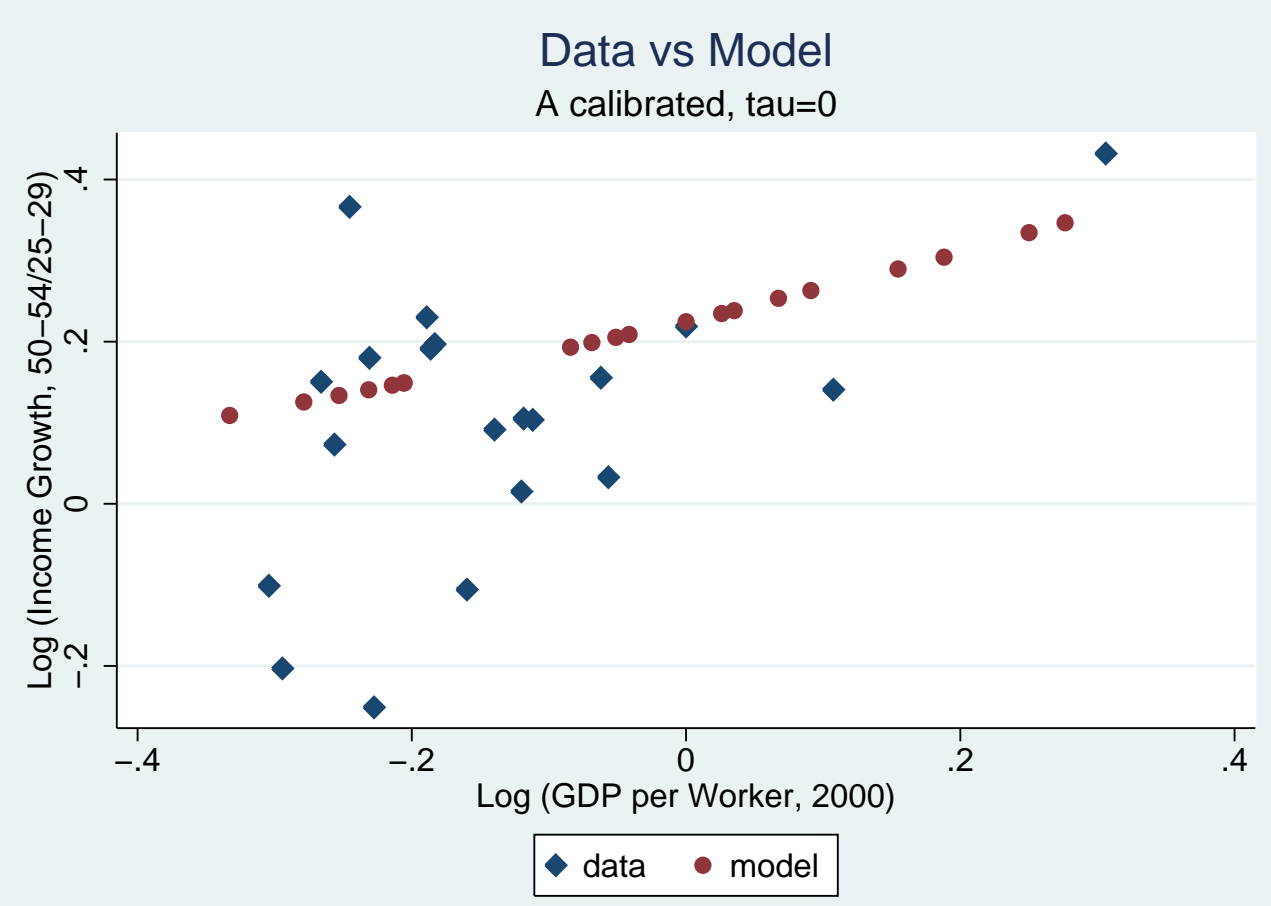

Figure 13

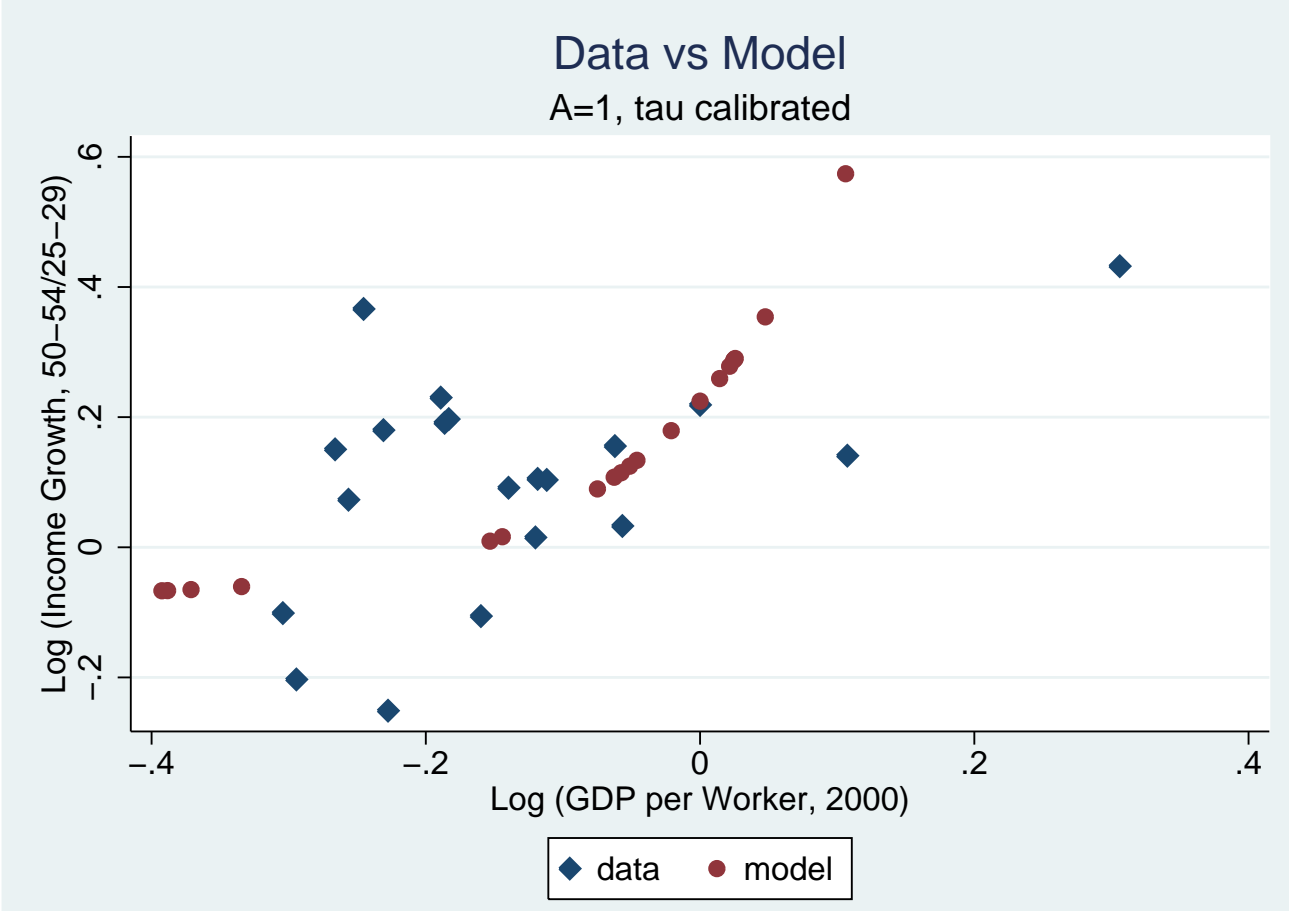

Figure 14 


\section{Appendix II: Balanced Growth}

Along a balanced growth path (i) growth rates are constant; (ii) the growth rate in output equals the growth rate in labor and managerial income; (iii) growth in aggregate skill investment is the same as the growth rate in output; (iv) the capital-output ratio is constant; (v) the fractions of managers and workers are constant (i.e. $z^{*}(t)=z^{*}$ for all $t$ ); (vi) factor prices are constant.

We find the growth rate in output per person $(g)$ and initial managerial skills $\left(g_{z}\right)$ consistent with (i)-(vi), given a growth rate in exogenous productivity $\left(g_{A}\right)$. Specifically, we show that there is a balanced growth path if and only if initial managerial skills grow at a specific rate determined by exogenous productivity growth.

From the properties of the plant's technology, it follows that

$$
1+g=\left(1+g_{A}\right)\left(1+g_{z}\right)^{1-\gamma}\left(1+g_{k}\right)^{\alpha \gamma}
$$

where $g_{k}$ stands for the growth rate of capital per person. It follows that

$$
1+g=\left(1+g_{A}\right)^{\frac{1}{1-\alpha \gamma}}\left(1+g_{z}\right)^{\frac{1-\gamma}{1-\alpha \gamma}}
$$

We proceed now to find the rate of growth of managerial skills that is consistent with a balanced-growth path. We denote by $g_{z}^{*}$ such growth rate. Note that if such path exists, then the age profile is shifted by a time-invariant factor $\left(1+g_{z}^{*}\right)$. That is,

$$
\frac{z_{j}(t+1)}{z_{j}(t)}=\left(1+g_{z}^{*}\right)
$$

for all $j=1, \ldots J_{R}-1$. It follows that we can infer the value of $g_{z}^{*}$ from the first-order conditions for skill investments of two cohorts of age $j \leq J_{R}-2$, at two consecutive dates. In particular, the first-order condition for decisions at the penultimate period of the working life cycle must hold along a balanced-growth path. From (13), it follows:

$$
\left(\frac{1}{1+g_{z}^{*}}\right)^{\theta_{1}}\left(\frac{1}{1+g}\right)^{\theta_{2}-1}=\left(1+g_{A}^{*}\right)^{\frac{1}{1-\gamma}}\left(\frac{1}{1+g}\right)^{\frac{\gamma(1-\alpha)}{1-\gamma}}
$$


In deriving the expression above, we used the fact that along a balanced growth path, the rate of return is constant and that the growth in output per capita, $g$, equals the growth rate in skill investments and the growth rate in wage rates. Solving for $g_{z}^{*}$ in (25), we obtain:

$$
1+g_{z}^{*}=(1+g)^{\frac{\gamma(1-\alpha)+\left(1-\theta_{2}\right)(1-\gamma)}{\theta_{1}(1-\gamma)}}\left(\frac{1}{1+g_{A}}\right)^{\frac{1}{\theta_{1}(1-\gamma)}}
$$

Substituting (26) in (24), after algebra we obtain

$$
1+g=\left(1+g_{A}\right)^{\psi}
$$

where $\psi$

$$
\psi \equiv \frac{1-\theta_{1}}{\gamma(1-\alpha)+\left(1-\theta_{2}\right)(1-\gamma)-\theta_{1}(1-\alpha \gamma)}
$$

Comments Several points are worth noting from the expression above. First, there is balanced growth path with positive growth in per capita output as long as $\theta_{1} \in[0,1)$. Second, all the same, the growth rate in output per capita increases with $\theta_{2}$ : as the importance of investments in the production of new skills increases, the growth rate in output per capita increases as well. Indeed, as $\theta_{2} \rightarrow 0$,

$$
\psi \rightarrow \frac{1}{1-\alpha \gamma}
$$

That is, the growth rate approaches the growth rate with exogenous skill investments given by the reciprocal of one minus the capital share.

Finally, as the span-of-control parameter approaches 1,

$$
\psi \rightarrow \frac{1}{1-\alpha},
$$

which results in the growth rate of a standard economy with constant returns in capital and labor. 


\section{Appendix III: Occupational Transitions}

In the benchmark economy presented in detail in Section 3, each individual chooses his/her occupation, whether to be a worker or a manager, at the start of his/her life and this decision is irreversible. In this Appendix, we first document facts on transitions between managerial and non-managerial occupations, and then build and calibrate a model economy that allows agents to switch between occupations. Finally, we study, as we did in sections 5.1 and 5.2 , the effects of changes in economy-wide productivity $(\bar{A})$ and the size dependence of distortions.

\subsection{Data on Occupational Transitions}

In order to compute transitions between managerial and non-managerial occupations in the United States, we use data from the Outgoing Rotation Groups of the Current Population Survey (CPS) for 1990-2010 period. Every household (address) that enters the CPS is interviewed for 4 consecutive months, then ignored (rotated out) for 8 months, and then interviewed again (rotated in) for 4 more months. As a result, it is possible to have observation on a subset of CPS sample that is one year apart. We follow a standard matching procedure, specified in Shimer (2012), based on matching households with the same identification code, as long as household members' characteristics (age, sex, race and education) are consistent between two points in time. The sample consists of individuals aged 25-64 who work at least 30 hours a week.

Based on matched households, we compute the fraction of individuals between ages 25$29,30-34, \ldots, 60-64$ who transit from a managerial (non-managerial occupations) to a nonmanagerial (managerial) occupation within a year. A transition from managerial (nonmanagerial) to non-managerial (managerial) occupation occurs if in month $t$ a worker reports an occupation that belongs to the set of managerial (non-managerial) occupations, while in month $t+12$ he/she reports an occupation that belongs to the set of non-managerial (managerial) occupations. The classification that we use to distinguish between managerial and non-managerial occupations is detailed in Section 2. If a worker is not observed or does not report any occupation in the year, he is excluded from the sample we use to calculate the transitions. We report average yearly transitions for 1990-2010 period.

Figure 1 shows the transitions between occupations in our data. As the figure shows, there are significant transitions between occupations from one year to the next. Each year about 
4-5\% of individuals with a non-managerial occupation moves to an managerial occupation, while a much larger fraction, 40-50\%, of individuals with a managerial occupation moves to a non-managerial occupation.

Figure 2 shows the fraction of individuals with a managerial occupation by different ages. We compute the fraction of managers using the U.S. Census and ACS; the same data sets that we used to calculate managerial and non-managerial income profiles in Section 2. In Figure 2, we report the fraction of managers averaged across four years (1990, 2000, 2005, and 2010) and normalize the fraction of managers at age 25-29 to 1. As the figure illustrates, the fraction of managers grows with age in the first part of the working life cycle, and then becomes approximately constant. There is nearly a $70 \%$ increase in the fraction of individuals with a managerial occupation between ages 25-29 and 45-49. After that, the fraction of managers is relatively constant until the retirement age.

\subsection{Model}

Consider now the following version of the model economy described in Section 3. Each individual is born with a managerial ability $z$, and individuals have access to a production technology to increase their managerial ability. This technology maps the current managerial ability and investment in human capital into a managerial ability level next period.

We introduce two changes into the basic model. First, we assume that accumulation of managerial skills is risky as in Huggett, Ventura and Yaron (2011). ${ }^{14}$ At the end of each period, all individuals receive a random shock, denoted by $\varepsilon$, that determines their level of skills next period in conjunction undepreciated skills and the production of new skills. In particular for a $j$-years old individual with a current skill level $z$ and investment $x$, the next period's skill level is given by

$$
z^{\prime}=\varepsilon\left[\left(1-\delta_{z}\right) z+B(j) z^{\theta_{1}} x^{\theta_{2}}\right] .
$$

Second, we allow both managers and workers to accumulate managerial human capital. In particular, we assume that at the start each period, all individuals, managers $(M)$ and workers $(W)$, decide whether to be a manager or a worker for that period. They make this decision before they observe $\varepsilon$. We assume that $\varepsilon$ is an iid, across time and individuals,

\footnotetext{
${ }^{14}$ Huggett, Mark, Ventura, Gustavo and Amir Yaron. "Sources of Lifetime Inequality." American Economic Review 100(7): 2923-54.
} 
shock distributed according to a cumulative distribution function $G_{o}(\varepsilon), o \in\{W, M\}$. Once the individuals make their occupation choice, they decide how much to consume, how much to save and how much to invest to enhance their skills, $x$. They make all these decisions again before they observe $\varepsilon$. After the investment decisions are made, $\varepsilon$ is realized and the individuals enter next period with their updated level of human capital. Then they again make an occupational choice decision and so on.

In this environment, although managerial skills do not affect the current income of workers, as they simply earn $w$, they still have an incentive to invest in their skills as a favorable $\varepsilon$ shock in the future can make them switch occupations next period. A manager, on the other hand, can decide to become a worker if his/her $\varepsilon$ was too low last period. We assume that switching occupation has no monetary or utility cost.

Consider the problem of an age- $j$ individual. At the start of the of the period, given his current skills $(z)$ and assets $(a)$, this individual decides whether to be a manager to a worker:

$$
V(a, z, j)=\max \left\{V^{M}(a, z, j), V^{W}(a, z, j)\right\}
$$

The value of being a manager $V^{M}(a, z, j)$ is given by

$$
V^{M}(a, z, j)=\max _{c, a^{\prime}, x}\left\{u(c)+\beta \int V\left(a^{\prime}, z^{\prime}(\varepsilon), j+1\right) d G_{M}(\varepsilon)\right\},
$$

subject to

$$
c+a^{\prime}+x \leq \pi(z, r, w)+(1+r) a
$$

and

$$
z^{\prime}=\varepsilon\left[\left(1-\delta_{z}\right) z+B(j) z^{\theta_{1}} x^{\theta_{2}}\right],
$$

where $\pi(z, r, w)$ is the profits of managers as defined by equation 6 in Section 3.1.

The value of being a worker $V^{W}(a, z, j)$, on the other hand, is given by

$$
V^{W}(a, z, j)=\max _{c, a^{\prime}, x}\left\{u(c)+\beta \int V\left(a^{\prime}, z^{\prime}(\varepsilon), j+1\right) d G_{W}(\varepsilon)\right\},
$$

subject to

$$
c+a^{\prime}+x \leq w+(1+r) a,
$$

and

$$
z^{\prime}=\varepsilon\left[\left(1-\delta_{z}\right) z+B(j) z^{\theta_{1}} x^{\theta_{2}}\right]
$$




\subsection{Parameter Values}

We follow the same calibration strategy as described in Section 4. In addition to the parameters listed in Table 1, we need to specify the functional forms for $G_{M}(\varepsilon)$ and $G_{W}(\varepsilon)$. We assume that both distributions are log-normal with mean zero and variances denoted by $\xi_{M}$ and $\xi_{W}$. In the model economy, these variance have implications for the fraction of managers in the labor force at each age as well as the relative age-earnings profile of managers. As a result, in order to calibrate these parameters we select two new targets: i) the fraction of managers at age 60-64 relative to the fraction of managers at age 25-29 and ii) an additional moment from the age-earnings profile - the relative earnings at age 50-54 (recall that relative incomes at ages 40-44 and 60-64 were already among the targets in Table 2). Table A3 presents the calibrated parameters of the model with occupational transitions. Table A4 compares the data and the model moments. Figures 2 and 3 show the fraction of managers by age and the age-earnings profiles of managers, respectively, in the model and the data. Model matches very well the age-earnings profiles of managers. It also captures endogenously the growth in the number of managers by age, although the growth is much more linear in the model than it is in the data.

With few exceptions parameter values in Table 1 and A3 are quite similar. In particular, the span of control parameter $\gamma$ is larger in the economy with occupational transitions. The volatility of skill shocks is larger for workers than it is for managers: the standard deviation for workers is $\xi_{W}=0.335$ while the standard deviation for managers is $\xi_{M}=0.215$. Since individuals are risk-averse and there is no explicit age-dependent preference for occupation, a smaller variance of shocks to managers' skills is needed to be consistent with the fact that the fraction of managers in the workforce grows by $63 \%$ from ages $25-29$ to ages $60-64$.

\subsection{Results}

To what extent are our baseline results change when we allow occupational changes over the life cycle? We now revisit the analysis of Section 5.4 and check how the economy reacts to changes in exogenous productivity and size dependency of the distortions. We report our findings in Tables A5 and A6.

We first proceed to gradually lower the exogenous TFP $(\bar{A})$ from the benchmark value of 1 to 0.7 . The effects of lower $\bar{A}$ values on aggregate output is very similar to ones we obtain 
for an economy without managerial transitions - compare Table 3 and Table A5. Relative earnings growth declines with a reduction of economy-wide productivity across steady states, although by a smaller magnitude than under the benchmark model.

These findings show the interaction of opposing effects. On the one hand, in the model economy with occupational transitions, individuals have an additional incentive to invest in skills given by skill-accumulation risk and the occupational choice it facilitates. As a result, skill investment does not decline as rapidly in response to reduction in $\bar{A}$ as in the baseline model - compare Table 3 and Table A5. Therefore, the response of managerial quality and relative earnings growth to exogenous productivity is more muted than in the baseline analysis. On the other hand, the fraction of managers in the labor force is almost constant for all levels of $\bar{A}$, whereas it rises slightly in the baseline model. The combination of these effects results in the response of output to $\bar{A}$ which is almost identical to the one in the baseline model.

We then gradually increase the size dependency of the distortion $(\tau)$ from the benchmark value of 0 to 0.08 . The effects on output, mean establishment size, relative earnings growth, fraction of managers, and managerial quality are very similar to those found for the baseline model - compare Table 4 and Table A6. As in the experiment with $\bar{A}$, the response of skill investment is much smaller compared to the baseline model. Clearly, size-dependent distortions reduce managers' incentives to invest in skills in order to earn higher managerial rents. However, individuals still use skill investment as an insurance against negative skill shocks. On top of that, given the option value of an occupational switch, workers aspiring to become managers keep investing in skills even at high levels of $\tau$. 
Table A3: Parameter Values (annualized)

\begin{tabular}{lc}
\hline \hline Parameter & $\underline{\underline{\text { values }}}$ \\
Population Growth Rate $(n)$ & 0.011 \\
Productivity Growth Rate $(g)$ & 0.025 \\
Depreciation Rate $(\delta)$ & 0.040 \\
\hline Importance of Capital $(\alpha)$ & 0.386 \\
Returns to Scale $(\gamma)$ & 0.844 \\
Mean Log-managerial Ability $\left(\mu_{z}\right)$ & 0 \\
Dispersion in Log-managerial Ability $\left(\sigma_{z}\right)$ & 3.01 \\
Discount Factor $(\beta)$ & 0.931 \\
Skill accumulation technology $(\theta)$ & 0.862 \\
Skill accumulation technology $\left(\delta_{\theta}\right)$ & 0.067 \\
Skill accumulation technology $\left(\theta_{1}\right)$ & 0.686 \\
Skill accumulation technology $\left(\theta_{2}\right)$ & 0.461 \\
Skill accumulation technology $\left(\delta_{z}\right)$ & 0.008 \\
Std deviation of skill shocks, managers $\left(\xi_{M}\right)$ & 0.215 \\
Std deviation of skill shocks, workers $\left(\xi_{W}\right)$ & 0.335 \\
\hline \hline
\end{tabular}

Note: Entries show model parameters calibrated for the model with occupational transitions. See text for details. 
Table A4: Empirical Targets: Model and Data

\begin{tabular}{lcc}
\hline \hline Statistic & $\underline{\text { Data }}$ & $\underline{\text { Model }}$ \\
Mean Size & 17.9 & 17.7 \\
Capital Output Ratio & 2.33 & 2.33 \\
Managerial Income $(40-44 / 25-29)$ & 1.18 & 1.17 \\
Managerial Income $(50-54 / 25-29)$ & 1.24 & 1.26 \\
Managerial Income (60-64/25-29) & 1.25 & 1.24 \\
Fraction of Managers (60-64/25-29) & 1.63 & 1.63 \\
\hline Fraction of Establishments & & \\
1-9 workers & 0.725 & 0.757 \\
10-20 workers & 0.126 & 0.108 \\
20-50 workers & 0.091 & 0.076 \\
50-100 workers & 0.032 & 0.028 \\
100+ workers & 0.026 & 0.031 \\
Employment Share & & \\
1-9 workers & 0.151 & 0.163 \\
10-20 workers & 0.094 & 0.092 \\
20-50 workers & 0.164 & 0.142 \\
50-100 workers & 0.128 & 0.120 \\
100+ workers & 0.462 & 0.483 \\
\hline
\end{tabular}

Note: Entries show the empirical targets used in the quantitative analysis and the model's performance in the model with occuppational transitions. The fraction of establishments with 1-9 and $100+$ workers, and the employment shares with 1-9 and 100+ workers are explicit targets. See text for details. 
Table A5: Effects of Economy-Wide Productivity

\begin{tabular}{lcccc}
\hline \hline Economy-Wide Productivity & $\bar{A}=1$ & $\bar{A}=0.9$ & $\bar{A}=0.8$ & $\bar{A}=0.7$ \\
\hline Statistic & & & & \\
Output & 100 & 84.5 & 68.6 & 55.6 \\
Mean Size & 17.7 & 17.7 & 17.6 & 17.3 \\
Investment in Skills & 100 & 93.5 & 85.9 & 80.8 \\
Investment in Skills (\% Output) & 8.1 & 8.9 & 10.1 & 11.7 \\
Number of Managers & 100 & 99.7 & 100.5 & 102.0 \\
Managerial Quality & 100 & 98.0 & 94.6 & 91.2 \\
Employment Share (100+) & 0.48 & 0.48 & 0.47 & 0.46 \\
Relative Earnings Growth $(\hat{g})$ & 0.23 & 0.19 & 0.17 & 0.10 \\
\hline \hline
\end{tabular}

Note: Entries show the effects on displayed variables associated to exogenous reductions in the level of economy-wide productivity $(\bar{A})$ across steady states. Column 2 reports benchmark values $(\bar{A}=1)$. Columns $3-5$ report the changes emerging from reducing $\bar{A}$ below the benchmark value. See text for details.

Table A6: Effects of Size-Dependent Distortions

\begin{tabular}{lccccc}
\hline \hline Size Dependency $(\tau)$ & 0 & 0.02 & 0.04 & 0.06 & 0.08 \\
Tax Wedge $\left(\frac{1-T(5 \bar{y})}{1-T(y)}\right)$ & 1 & 0.97 & 0.94 & 0.91 & 0.88 \\
\hline & & & & & \\
Statistic & 100.0 & 93.0 & 83.7 & 78.6 & 73.3 \\
Output & 17.7 & 13.0 & 10.1 & 8.1 & 6.8 \\
Mean Size & 100.0 & 87.1 & 78.6 & 75.1 & 72.8 \\
Investment in Skills & 8.1 & 7.5 & 7.6 & 7.7 & 8.0 \\
Investment in Skills (\% Output) & 100.0 & 136.1 & 174.6 & 217.5 & 261.6 \\
Number of Managers & 100.0 & 72.2 & 54.9 & 43.7 & 36.0 \\
Managerial Quality & 0.48 & 0.34 & 0.22 & 0.13 & 0.07 \\
Employment Share (100+) & 0.23 & 0.10 & 0.02 & -0.01 & -0.05 \\
Relative Earnings Growth $(\hat{g})$ & & & & & \\
\hline \hline
\end{tabular}

Note: Entries show the effects on displayed variables associated to size-dependent distortions across steady states. Column 2 reports benchmark values $(\tau=0)$. Columns 3-6 report the changes emerging from increasing the size dependency of distortions. See text for details. 


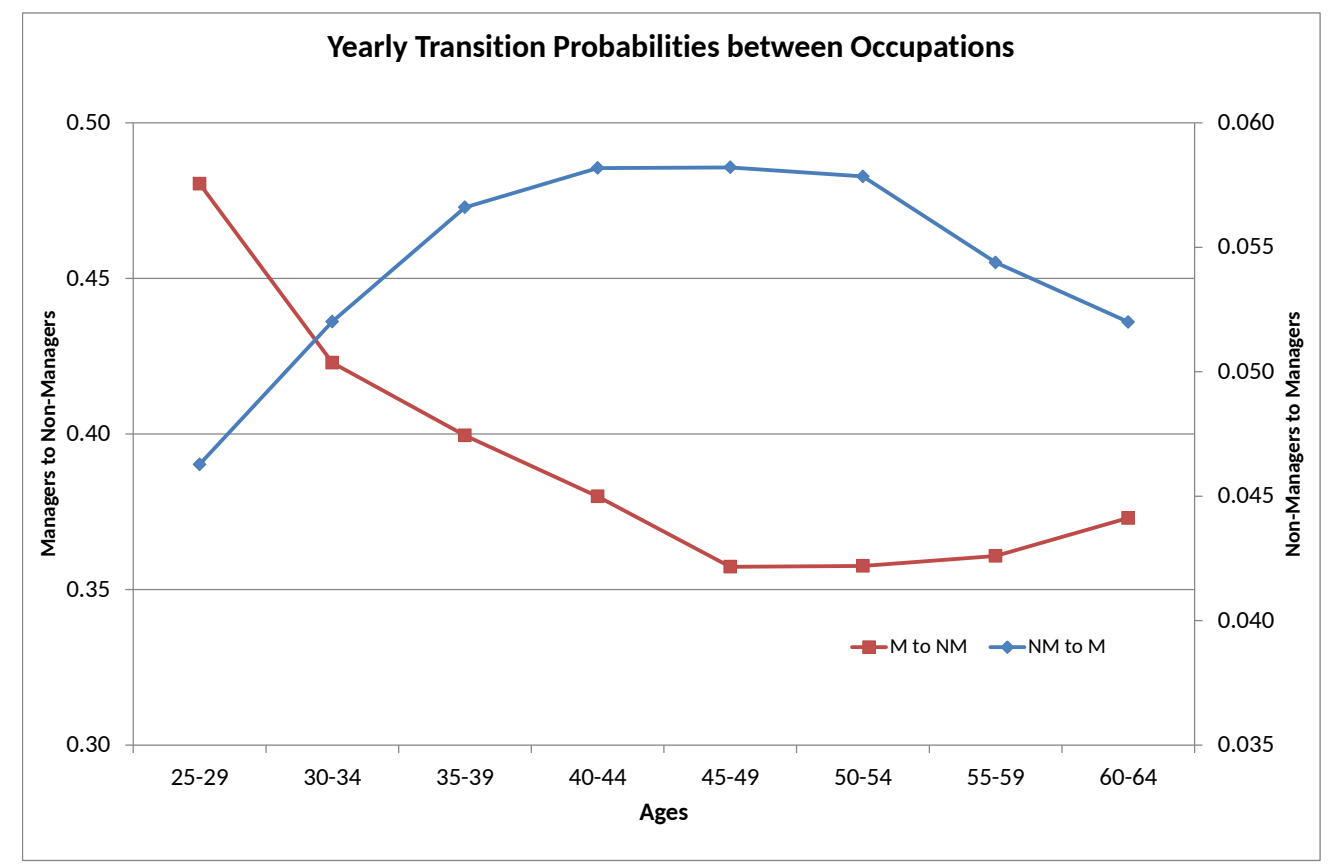

Figure 1

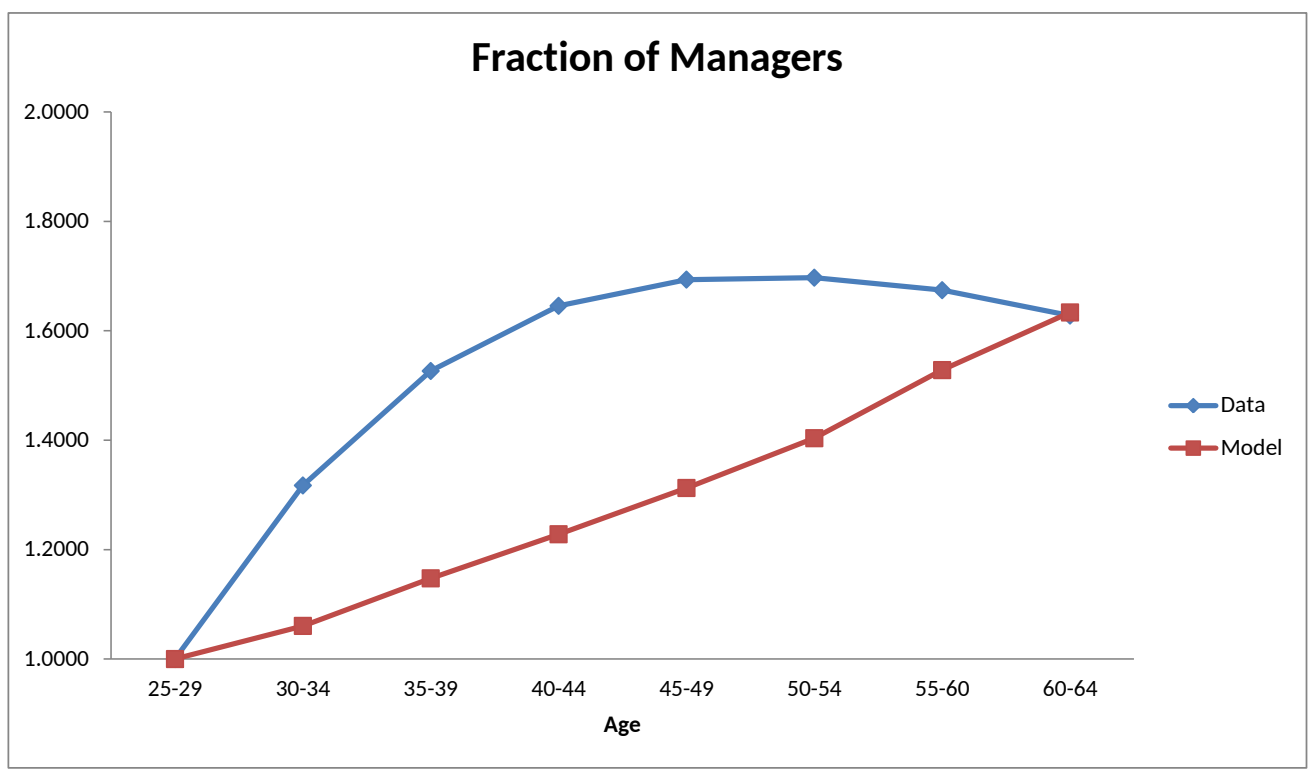

Figure 2 


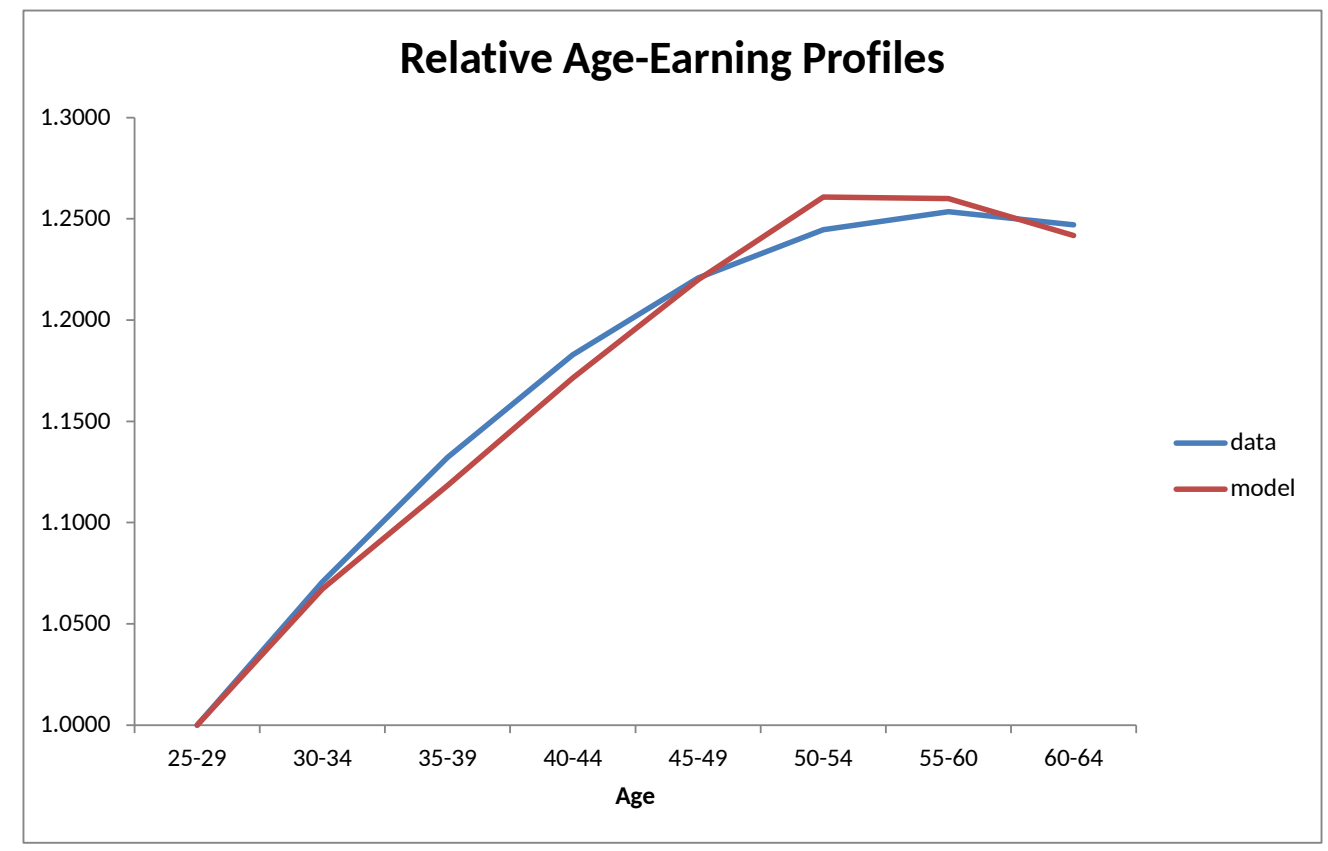

Figure 3 